\title{
Augmentative and Alternative Communication for Children with Intellectual and Developmental Disability: A Mega-Review of the Literature
}

\author{
Becky Crowe $^{1}$ (D) $\cdot$ Wendy Machalicek ${ }^{1} \cdot$ Qi Wei $^{1} \cdot$ Christine Drew $^{2} \cdot$ Jay Ganz $^{3}$
}

Accepted: 11 February 2021 / Published online: 31 March 202

(C) The Author(s), under exclusive licence to Springer Science+Business Media, LLC, part of Springer Nature 2021

\begin{abstract}
Establishing evidence- and research-based practices relies upon research synthesis of individual studies in reviews and meta analyses. Further summarizing scientific evidence about a specific topic by synthesizing reviews is an area of need to determine practices that have a strong evidence base and to identify areas of methodological weakness and gaps in the literature. A mega-review of literature reviews, systematic reviews, and meta-analyses on interventions using aided augmentative and alternative communication (AAC) interventions for children with intellectual and developmental disabilities from 2000 to mid-2020 was conducted. Participant and interventionist demographics, interventions, settings, outcomes, and recommendations of each review were reported and summarized. A MeaSurement Tool to Assess systematic Reviews Revised (AMSTAR 2; Shea et al., 2017) was used to examine the methodological rigor of 84 included reviews. Over the past 20 years, published reviews have increased slightly in methodological rigor but demonstrate a number of methodological weaknesses that detract from the strength of evidence for AAC interventions with this population. Suggestions for improving the methodological rigor of literature reviews and areas for future research specific to AAC interventions are discussed.
\end{abstract}

Keywords Mega-review · Research synthesis · Augmentative and alternative communication $\cdot$ Aided communication $\cdot$ Developmental disabilities $\cdot$ Review

Becky Crowe

rcrowe@uoregon.edu

1 Department of Special Education and Clinical Sciences, University of Oregon, 1589 E 15th Street, Eugene, OR 97403, USA

2 Department of Special Education, Rehabilitation and Counseling, Auburn University, Auburn, AL, USA

3 Department of Special Education and Educational Psychology, Texas A\&M University, College Station, TX, USA 
Individuals with complex communication needs (CCN) comprised approximately $1.3 \%$ of the total United States population in 2013, or approximately 4 million people (Beukelman \& Mirenda, 2013); however, this figure has likely increased along with the increasing incidence rates of autism spectrum disorder (ASD) and other disabilities impacting communication and language skills (Light \& McNaughton, 2012). Augmentative and alternative communication (AAC) interventions for children with intellectual and developmental disabilities and complex communication needs increase functional communication skills (Drager et al., 2010), increase language and social competence (Light et al., 2003), and can increase natural speech in some individuals (Millar et al., 2006). The ability to effectively and efficiently communicate wants and needs and actively participate in social exchanges can improve quality of life and independence (Chan \& Zoellick, 2011). Communication increases social closeness, or relationships between individuals characterized by positive exchanges, mutuality, sharing, and mutual enjoyment (Howes, 1983).

AAC includes unaided systems such as manual sign and gestures as well as aided systems such as the Picture Exchange Communication System (PECS; Bondy \& Frost, 1994) and speech generating devices (SGD). Aided AAC systems include high tech speech generating aided communication systems (e.g. apps on Apple ${ }^{\mathrm{TM}}$ devices, GoTalk9+, AMDi Tech/Plus 32, ablenet® BIGmack; Logan, Iacono, \& Trembath, 2017) and low tech communication systems (e.g. PECS, eye gaze board, symbols on a ring or in a notebook). Aided AAC specifically refers to systems requiring external or additional supports outside of the speaker's body. AAC modalities refers to the different systems of AAC: aided or unaided, low or high tech, and the different access methods (e.g. eye gaze, touchscreen, head pointer). Unaided AAC systems such as gestures and manual sign require gross and fine motor skills (Fuller, Lloyd, \& Stratton, 1997), functional use of hands and fingers and trained communication partners familiar with idiosyncratic gestures and sign languages (Mirenda, 2003). Aided AAC systems are most often selected for individuals with CCN (Mirenda, 2001) due to their accommodation of alternate access for individuals with fine motor impairments, intelligibility to unfamiliar listeners without training, and visual symbols that resemble their referents (Mirenda, 2001).

The growing number of reviews that summarize the extant AAC intervention literature has utility in informing clinical decisions and aiding policymakers in making research-based decisions about educational and medical policies. However, reviews of studies are subject to publication bias (Shea et al., 2007, 2017) and can include studies of poor methodological quality (Sharif et al., 2013). Synthesizing results across systematic reviews, literature reviews, and meta-analyses is difficult due to the use of different methodologies, conceptual frameworks, and, if used, effect size calculations (Shea et al., 2007, 2017). Moreover, methodological procedures, rigor, and purposes and findings of systematic reviews often differ, contributing to potential practitioner confusion in determining whether a particular intervention or practice has sufficient evidence to warrant adoption (Wells \& Littell, 2009). A previous practitioner megaanalysis on special education interventions summarized 18 meta-analyses to indicate which interventions have the largest effect sizes. This paper was the first to indicate a need for synthesizing syntheses of research to inform practices, encourage selection of highly effective interventions for use with individuals with disabilities, and recommend discontinuation of use of ineffective practices (Forness et al., 1997). 
Mega-review methodology originated in the healthcare field as a method by which researchers gather systematic reviews into a single synthesis of combined findings about an intervention or topic of interest (e.g., Dragioti et al., 2017; Seida et al., 2009). Researchers conduct mega-reviews, also called umbrella reviews, to collect, collate, and summarize the evidence base provided by systematic reviews of individual studies to present a cohesive synthesis of the extant literature, identify gaps and blind spots with a field's published evidence base, and identify promising practices for researchers and practitioners (Ioannidis, 2009). Mega-reviews also provide an opportunity to examine the methodological quality of included reviews. Mega-review methodology applied to AAC interventions is very limited: to date, there is a single overview of review studies (Nam et al., 2018) examining five reviews on AAC for individuals with developmental disabilities. This mega-review was limited to reviews of single case research designs comparing AAC systems and did not assess review methodological quality. There has been an increase of published systematic reviews and meta-analysis in recent decades, thus a systematic review of reviews in the area of AAC implementation is warranted.

What Works Clearinghouse (WWC) standards for single-case research design studies provide rigorous methodological requirements for researchers that are used to determine study quality and establish evidence-based practices (Kratochwill et al., 2010). There are no similarly clear standards for conducting and reporting reviews of literature. The Preferred Reporting Items for Systematic Reviews and Meta-Analysis (PRISMA) guidelines focus on reporting of randomized control trial data using quantitative methodologies (Moher et al., 2009). There is no quality indicator measure to compare review quality across group and single case research designs. Due to the inconsistent reporting of quality of evidence on AAC interventions, researchers and clinicians are unable to make clear and conclusive recommendations to practitioners and families about best practices or research-based interventions (e.g., Ganz et al., 2017; Holyfield et al., 2017).

The Scottish Intercollegiate Guidelines Network (SIGN) checklist was developed to assess methodological quality of systematic reviews and meta-analyses of single case research (Manolov et al., 2017); however, SIGN does not address methodological quality of other design types. A MeaSurement Tool to Assess systematic Reviews (AMSTAR) was developed by Shea et al. (2007) and revised to include nonrandomized studies (AMSTAR 2; Shea et al., 2017). AMSTAR 2 has been evaluated for inter-rater reliability (median Cohen's kappa range: 0.51-0.71) and found to have moderate to substantial agreement (Lorenz et al., 2019; Shea et al., 2017). AMSTAR 2 was also found to have validity of appraising systematic reviews and determined to be easy to administer (Lorenz et al., 2019; Pieper et al., 2015) and had good inter-rater reliability with the risk of bias in systematic reviews tool (Pieper et al., 2019).

The purposes of this mega-review are to summarize published peer-reviewed literature reviews about aided AAC interventions that included children with developmental disabilities, to present an overview of the most frequently used aided AAC interventions, and to appraise each review's quality using AMSTAR 2. The following research questions were asked: (a) what is the methodological quality of peer-reviewed published literature reviews on interventions for teaching communication skills using aided AAC to children with developmental disabilities and complex communication needs; (b) has the methodological quality of reviews of aided AAC interventions for 
children with developmental disabilities and complex communication needs changed over time; (c) how are aided AAC interventions described regarding participants, interventionists, and interventions; (d) what are the review-reported communications outcomes of aided AAC interventions and review-reported recommendations for future research; and (e) what intervention methodologies have been used to produce and report knowledge about aided AAC interventions for children with developmental disabilities and complex communication needs?

\section{Method}

A mega-review of the literature on interventions for individuals with $\mathrm{CCN}$ who use aided AAC was conducted to summarize the published literature and provide guidance to researchers on areas of further research, ways to increase methodological rigor, and any blind spots within the literature. Aided AAC was operationally defined as AAC requiring materials external to the body, such as icons and/or voice-output systems. This mega-review was conducted as a systematic review of literature reviews including systematic reviews, meta-analyses, and narrative reviews with systematic and replicable methods replacing individual studies. By completing a review of reviews, the authors aimed to summarize extant literature and identify areas commonly featured in aided AAC research and bring to light areas of need identified by authors reviewing individual studies. Unpublished and gray literature, including dissertations, book chapters, and reports, were excluded from this mega-review due to limiting searches to peerreviewed journals.

\section{Search Strategy}

The electronic databases ERIC, PsycINFO, and Academic Search Premier were systematically searched by the first author using combinations of the following free term keywords: (a) "augmentative and alternative communication or AAC", OR (b) "assistive technology", OR (c) "aided communication", AND (a) "literature review”, OR (b) "systematic review", OR (c) "meta-analysis". In this paper, meta-analyses referred to reviews that statistically combine data from multiple studies, assess effect sizes, and analyze research results (Uman, 2011) and literature review referred to a review, including systematic reviews, that reported completing systematic searches but did not explicitly declare a priori methods or research question(s) and also did not use meta-analysis procedures. The following restrictions were placed on the electronic searches: (a) peer-reviewed publications; (b) published between January 1, 1999 and August 1, 2020 to capture the last 20 years of research in this area; (c) published in English; and (d) no dissertations, books, book chapters, or government reports. Narrative and scoping reviews (e.g. Schlosser \& Sigafoos, 2006) were excluded from the present mega-review due to AMSTAR 2 being developed for use with systematic reviews/meta-analyses. Scoping reviews were excluded due to their not being research question-driven, disparities in reporting replicable methods of the review process, and scoping reviews are often not intended to synthesize research evidence (Munn et al., 2018). 
Initial searches returned 1215 articles. Titles and abstracts of each article were reviewed by the first author after removal of duplicates, and 185 met inclusion criteria. Hand searches of the most frequently appearing journals (i.e., Augmentative and Alternative Communication and Journal of Speech, Language, and Hearing Research) were completed by the first author in July 2018, looking at titles and keywords for "review" or "summary" and "AAC" or "assistive technology". The journal Augmentative and Alternative Communication was searched from January 1999-August 1, 2020 and yielded 1 new article. A hand search of the Journal of Speech, Language, and Hearing Research was conducted from January 1999 and August 1, 2020; no new articles were identified. The first author also completed ancestral searches by reviewing the articles cited by reviews identified for inclusion and published in the last 20 years; no new articles were identified. Four reviews identified via expert nomination were included for full text analysis. During title and abstract screening, 15 scoping and qualitative reviews were excluded.

During full text coding, each article was reviewed by the first author against the following inclusion criteria: (a) literature review, systematic review, or meta-analysis; (b) replicable methods that included single case or group design research methodologies; (c) reported or addressed use of aided AAC; (d) reported communication outcomes, operationalized as a change in receptive or expressive communication skills (e.g. syntax, verbal operants, initiations, responses) for at least one participant per study; (e) included at least one participant diagnosed with a developmental disability; (f) reported at least one participant 0-18 years; and (g) evaluated the results of the studies or interventions using a narrative summary, table, or quantitative analysis.

A total of 185 reviews were identified that met inclusion criteria and were coded via full text review. During full text coding, 101 reviews were excluded. Reviews were excluded from analysis for the following reasons: (a) qualitative methodology $(n=8)$; (b) narrative reviews without systematic replicable methods $(n=11)$; (c) scoping reviews $(n=5)$; (d) participants' principal diagnosis was sensory impairment $(n=6)$; (e) no communication outcomes reported $(n=36)$; (f) only adult participants $(n=5)$; $(\mathrm{g})$ only unaided AAC used in interventions $(n=11)$; and (h) duplicates $(n=19)$. Reviews that did not synthesize intervention results (Binger \& Light, 2008) or did not report intervention results were also excluded (e.g. Gevarter et al., 2013). Searches and application of inclusion and exclusion criteria are detailed in Fig. 1. A list of excluded reviews is available upon request. There were 84 reviews included in this mega-review. Population, intervention, comparator group, outcome, and study design (PICOS) information for this mega-review are depicted in Fig. 3, available in supplemental materials.

\section{Data Extraction}

The first author created a coding sheet in Microsoft Excel ${ }^{\mathrm{TM}}$ to code each article selected for full text review (available upon request). Variables and coding categories were identified through close reading of each review, then counted via event recording by the first author for each occurrence. Primary coded variables were (a) type of designs; (b) number of included studies; (c) age of participants; (d) participant and interventionist demographics; (e) type of intervention; (f) intervention setting; (g) interrater agreement; (h) generalization; (i) maintenance; (j) outcomes and findings reported 


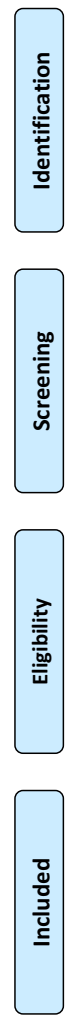

Records identified through database searching $(n=1,215)$
Additional records identified through other sources

Journal search $(n=17)$

Ancestral search $(n=76)$
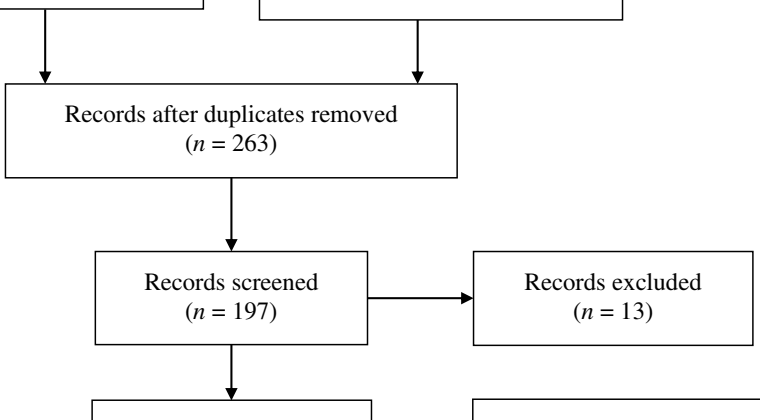

Full-text articles assessed for eligibility $(n=185)$

Expert nomination $(n=4)$

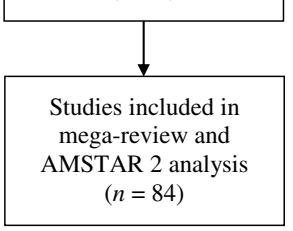

Full-text articles excluded $(\mathrm{n}=101)$

No communication outcomes $(n=$ 36)

No aided AAC $(n=11)$

Sensory impairment only $(n=6)$

No children participants $(n=5)$

Qualitative methods only $(n=8)$

Narrative review $(n=11)$

Scoping review $(n=5)$

Duplicates $(n=19)$

Fig. 1 PRISMA Diagram for mega-review

by review authors; (k) limitations; and (l) recommendations. Additional variables that were coded were: (a) participant race/ethnicity; (b) participant gender; (c) type of interventionist (e.g., clinician, teacher, or parent); (d) disability diagnoses; (e) intervention setting: and (f) type of AAC (e.g. PECS/PCS, SGD, mobile tablets as SGD. Specific types of SGD were coded but were aggregated due to a wide variety of devices and systems used over 20 years of technology development. Types of interfaces and complexity were not coded due to lack of reporting by review authors. Behavioral intervention was defined as the use of an intervention strategy based on principles of applied behavior analysis (e.g., forward chaining, prompt hierarchy, time delay). Due to intervention development and terminology evolution and inconsistent reporting of intervention strategies by review authors, specific intervention types were not coded. Variables were coded using key words and quantitative data reported by each review and hand-typed or copied and pasted into the Excel sheet. A complete coding form is available upon request.

Following coding for variables of interest, the first author coded each review using the AMSTAR 2 tool. Items not applicable to each review's included designs were coded "not applicable" and not calculated in total points possible (e.g., a literature review was coded not applicable for having done appropriate statistical analyses). AMSTAR 2 results were compared across reviews by calculating percent of points possible: number of items marked "Yes" or Partial Yes" divided by the total number of 
applicable items $\times 100$. Because the authors of AMSTAR 2 did not create guidance around cutoff levels for review quality, no reviews were excluded due to review quality.

\section{Reliability}

Search and inclusion reliability were independently conducted by the fourth author, an assistant professor in special education. Electronic database searches were completed using free term keywords and applying inclusion and exclusion criteria to titles and abstracts following a 1-h training via Zoom. Training procedures are available upon request and included modeling free term searches in each database, tracking number of hits per database, and applying inclusion and exclusion criteria to each title and abstract. Agreement across the three electronic databases averaged 93.3\% (range: $87.5 \%-98 \%$ ), calculated by the total number of agreements divided by the total number of agreements plus total number of disagreements $\times 100$ for each database. Disagreements at the title/abstract level were discussed until the two authors reached consensus on inclusion/exclusion of reviews.

Data extraction inter-coder agreement (ICA) was completed by random number generation to select $37 \%$ of reviews $(n=31)$ from an alphabetical list of included references. The third author, a special education doctoral student, compared a copy of the completed coding sheet for each review against review full text and marked each Excel cell for disagreement in red. Data extraction ICA was $98.26 \%$, calculated by dividing 396 agreements by 403 possible agreements $\times 100$. AMSTAR 2 coding agreement was similarly completed by the third author reviewing scores for another 31 randomly selected articles. The third author used a copy of the completed data codes and marked disagreements in red. Initial independent AMSTAR 2 coding ICA was $89.72 \%$, calculated by dividing 445 agreements by 496 possible agreements $\times 100$. Disagreements on variable coding and AMSTAR 2 ratings were discussed between the first and third authors until consensus was reached.

\section{Results}

Included reviews were coded according to reported variables and results are summarized in narrative form. Results were calculated by frequency count of variables per review and reported by content area. Most of the reviews that met inclusion criteria were identified as systematic reviews $(n=36)$, followed by literature reviews $(n=26)$ and meta-analyses $(n=22)$. Research designs encompassed solely single case research designs $(n=43)$, single case and group designs $(n=31)$, single case and group designs in combination with qualitative methodology $(n=6)$, mixed methods $(n=2)$, and not explicitly reported $(n=2)$. Table 1 aggregates how many reviews reported variables of interest such as type of designs, ages of participants, and type of AAC used. Reviews and meta-analyses reporting on the same studies or multiple publications about a single set of searches were counted as individual separate reviews, thus variables of interest could have been coded and counted multiple times. 
Table 1 Variables of Interest Reported by Reviews

Variables of interest

Number of reviews reported

Research design

Single case

Single case and group

$\begin{array}{ll}\text { Single case and group and qualitative methods } & 6\end{array}$

Mixed methods $\quad 2$

Not reported $\quad 2$

Review type

Systematic review $\quad 36$

Literature review $\quad 26$

Meta-analysis $\quad 22$

Other 4

Mega-review 1

Intervention type

Behavioral

$\begin{array}{ll}\text { Not behavioral } & 16\end{array}$

$\begin{array}{ll}\text { Not reported } & 7\end{array}$

Disability category

Autism spectrum disorder $\quad 62$

Other health impairment $\quad 36$

Developmental disabilities $\quad 34$

Intellectual disability $\quad 33$

$\begin{array}{ll}\text { Speech language impairment } & 7\end{array}$

Augmentative and alternative communication

$\begin{array}{ll}\text { Speech-generating device } & 38\end{array}$

iPad/iPod as speech-generating device $\quad 7$

PECS/picture communication symbols $\quad 34$

$\begin{array}{ll}\text { Other } & 15\end{array}$

Intervention setting

$\begin{array}{ll}\text { General education/inclusive classroom } & 37\end{array}$

$\begin{array}{ll}\text { Self-contained/special education classroom } & 23\end{array}$

Home $\quad 23$

Outpatient clinic 13

$\begin{array}{ll}\text { Other } & 28\end{array}$

Review reported:

Generalization $\quad 33$

Maintenance $\quad 30$

Social validity $\quad 5$

Age of participants

Birth - kindergarten/preschool $\quad 50$

Kindergarten - 6th grade/elementary $\quad 62$

6th grade - 12th grade/middle - secondary $\quad 55$

Adults 38

Note. Some reviews reported multiple characteristics of interest, e.g., children ages 3-21, which the author coded as participant ages of all four age categories listed, therefore, not all categories total 84 


\section{Participants}

The most commonly reported participant disability condition was autism spectrum disorder (ASD), reported by 62 reviews. Thirty-six reviews reported disabilities that fall under the disability category aggregate of other health impairments, including cerebral palsy and other reported conditions (e.g., epilepsy, cleft palate, behavior and attention disorders). Developmental disabilities $(n=34)$, intellectual disability $(n=33)$, and speech language impairment $(n=7)$ were the next most frequently reported participant disabilities. Reviews also reported that participants had multiple disability diagnoses or aggregated diagnoses as developmental disabilities. Participants in single-case research and group designs were mostly male, had a diagnosed disability impacting their functional communication, and were school-aged or 3-18 years old.

Due to variations in review reporting of ages and school levels, the authors created participant age categories of (a) birth through kindergarten or 0-5 years old $(n=50)$; (b) elementary school age of kindergarten through sixth grade or 6-10 years old; $n=62$ ); (c) adolescents 11-17 years old or sixth grade through twelfth grade $(n=55)$; and (d) adults or ages 18 years and up $(n=38)$. Reviews reported participants by numerical age as well as age category (e.g., elementary or secondary) and often reported multiple age categories, thus the sum of these categories exceeds 84 . In reporting participant demographics, four reviews included race/ethnicity data (Barton et al., 2017; Chung et al., 2012; Ganz et al., 2014a; Shire \& Jones, 2015), 31 reviews reported participant gender, and type of disability was reported in all 84 reviews.

\section{Interventionists}

Most reviews did not report on (a) study interventionists other than the researchers; (b) participant demographics, especially data specific to race or ethnicity; (c) interventionist or researcher demographic information; or (d) the identity, expertise or training level, or role within the study of the interventionist. Fifteen reviews reported a teacher or paraprofessional as the interventionist, 13 reviews reported the researcher was the sole interventionist, and 9 reviews reported parent interventionists. One review reported the education level and race/ethnicity of communication partners (Shire \& Jones, 2015).

\section{Settings}

Interventions took place in (a) a general education or inclusive classroom setting ( $n=$ $37)$; (b) other settings such as residential facility or hospital $(n=28)$; (c) a selfcontained or special education classroom $(n=23)$; (d) participant's home $(n=23)$; or (e) an outpatient clinic setting $(n=13)$.

\section{AAC Modalities and Interventions}

The most frequently reported AAC modalities were SGDs $(n=38)$, PECS or picture symbols $(n=34)$, other $(n=15)$, and specified iPad ${ }^{1} /$ iPod as an SGD $(n=7)$. The use of

\footnotetext{
${ }^{1}$ The iPad and iPod are products of Apple Computers Inc., Cupertino, CA, www.apple.com
} 
behavioral interventions or strategies, such as PECS (Tincani \& Devis, 2011); prompting, shaping, and modified interrupted chain procedures (Alwell \& Cobb, 2009); practitioner-implemented functional communication training focusing on single mands, intraverbals, or tacting (Alzrayer et al., 2014), was reported by most reviews $(n=65)$. Sixteen reviews reported interventions that were not explicitly based on principles of behavior, and seven reviews did not report enough information about the interventions of included studies to determine whether behavioral strategies were used.

Review authors determined some AAC interventions to have enough welldesigned studies to be established as evidence-based practices. These included PECS (Tincani \& Devis, 2011), the use of assistive technology for activities of daily living (Cumming \& Draper Rodríguez, 2017), the use of high-tech AAC to teach social communication skills (Morin et al., 2018), computer-aided instruction (Barton et al., 2017), tablet-based video modeling (Hong et al., 2017), aided AAC modeling (Lynch et al., 2018), and inclusive education for increasing communication skills (Alquraini \& Gut, 2012). Claims regarding evidence-based practices were made by reviews on the basis of moderate to strong intervention effects on dependent variables of interest and by quality of evidence analyses; however, reviews used varied effect size calculations and different evaluations of methodological rigor from one another.

Interventions with sufficient evidence and quality to meet the criteria of emerging evidence-based practices according to review authors included aided AAC input in which the communication partner/interventionist also uses the AAC system (Branson \& Demchak, 2009; Ganz et al., 2012b; Sennott et al., 2016; Shire \& Jones, 2015; Therrien et al., 2016), AAC-based interventions to reduce challenging behavior (Walker \& Snell, 2013; Walker et al., 2018), tablets and mobile devices as AAC (Cumming \& Draper Rodríguez, 2017; Kim \& Kimm, 2017; Lorah et al., 2015; Stephenson \& Limbrick, 2015), and using symbols and icons to represent words and phrases in aided AAC systems (Roche et al., 2014).

Reviews that compared different types of AAC (e.g., comparison of high- to lowtech systems) found that PECS compared to speech-generating devices did not have significant differences in communication outcomes (Ganz et al., 2014). Greater communication skills gains were found for individuals using aided compared to unaided AAC, and individuals with ASD made greater gains in communication skills than individuals with intellectual disabilities (Holyfield et al., 2017). A systematic review of studies comparing participant preference for SGDs compared to other modes of AAC found that $67 \%$ of participants who had developmental disabilities had some degree of preference for using SGD and 33\% of participants preferred picture exchange (van der Meer et al., 2011).

\section{Generalization, Maintenance, and Social Validity}

Very few reviews reported maintenance or generalization data from the included studies, a criticism noted by many review authors about individual studies and which prompted calls to action for researchers to program for and report these data. Reviews that measured social validity $(n=5)$, generalization $(n=33)$, and maintenance $(n=30)$ were in the minority of the total included 84 reviews. 


\section{Experimental Designs}

AAC interventions for individuals with intellectual and developmental disabilities who have complex communication needs were most frequently studied in single-case research designs $(n=38)$, using primarily multiple-baseline or multiple probe designs. Alternating treatment or multielement designs were used to compare contexts, communication partners, and most frequently used to compare investigate replacement of challenging behavior with functional communication responses.

Reviews including group designs investigated effects of PECS interventions (e.g., Allen et al., 2017; Alsayedhassan et al., 2016; Flippin et al., 2010; Ostryn et al., 2008; Preston \& Carter, 2009) or comparisons of different types of AAC (e.g., Brunner \& Seung, 2009; Lancioni et al., 2007; Branson \& Demchak, 2009; Schlosser \& Wendt, 2008). Summaries of type of AAC intervention reported outcomes and recommendations made by review authors are presented in Table 2, available in supplemental materials.

\section{Review Methodological Quality}

Since 2001, when the first systematic review specific to AAC and assistive technology was published (Lancioni et al., 2001), review quality, as evaluated by AMSTAR 2, has been highly variable but has improved over time. There was considerable variation in review quality, but an overall increasing trend, as shown in Fig. 2, which indicates greater adherence to best practices in completing systematic reviews and meta-analyses over time.

Areas of strength in methodological quality included explicitly stating the research question and reporting information on participants, intervention, comparison groups, and outcomes $(n=73)$, explicitly established the methods before conducting the review $(n=80)$, explained inclusion/exclusion criteria $(n=81)$, comprehensively searched at least two databases, conducted a reference search, and searches within 24 months of completion of the review $(n=80)$, and described included studies with sufficient detail $(n=78)$. Data on the percent of reviews that scored a "yes" for each AMSTAR 2 item are reported in Table 3, available in supplemental materials. Areas of need included providing a list of excluded studies and reasons for exclusion $(n=4)$, accounting for risk of bias in individual studies when interpreting the review results $(n=22)$, and providing a satisfactory explanation for heterogeneity in the results of the review $(n=21)$.

The reviews with the highest AMSTAR 2 scores were primarily systematic reviews and meta-analyses, which could reflect the validity of the tool to assess the methodological quality of group designs. These reviews were all published after the introduction of AMSTAR, and were all published in the last 10 years with one exception (Rispoli et al., 2010). The 11 highest scoring reviews scored $80 \%$ or greater of possible points on AMSTAR 2, and the four next top scoring reviews achieved $77 \%$ of items possible. Each included review's AMSTAR 2 scores and total achieved are shown in Table 4, available in supplemental materials.

\section{Discussion}

This mega-review synthesizes information reported by literature reviews, meta-analyses, systematic reviews, and one mega-review on aided AAC interventions for children with 
Table 2 Interventions, Outcomes, and Recommendations Reported in Each Included Review

\begin{tabular}{ll}
\hline Review & Intervention \\
\hline Allen et al., (2017). & Aided augmented input. \\
Alper \& Raharinirina, & $\begin{array}{c}\text { Effectiveness of assistive } \\
\text { technology: } 5.88 \% \text { of } \\
\text { (2006). }\end{array}$ \\
& $\begin{array}{l}\text { included studies on AAC (n). } \\
\text { Alsayedhassan et al. } \\
\text { (2016). }\end{array}$ \\
& $\begin{array}{l}\text { Picture Exchange } \\
\text { (PECS). }\end{array}$
\end{tabular}

Alwell \& Cobb, (2009). Social and communication interventions for secondary-aged youth with disabilities. AAC subgroup ( $n=5)$ : milieu teaching, prompting, shaping, modified interrupted chain procedures.

Alzrayer et al., (2014). Mobile tablet use in communication interventions with individuals with autism spectrum disorder and other developmental disabilities.

Andzik et al., (2016). $\quad \begin{aligned} & \text { Practitioner implemented } \\ & \text { functional communication } \\ & \text { training. }\end{aligned}$

Anttila et al., (2012). Overview of systematic reviews of assistive technology interventions across recreation, vocational support, and communication.

de Barbosa et al., (2018).

\section{Outcomes}

Receptive and expressive vocabulary skills increased, pragmatic skills increased. Aided input more effective than non-aided.

Very young individuals with disabilities are not receiving assistive technology. Participants mostly children: $25 \%$ of participants over 22 years. Assistive technology interventions resulted in skill improvement in $67.65 \%$ of studies.

Overall positive and successful outcomes: 8 out of 13 studies reported mastery of PECS.

Increase in communication skills in all studies and overall mean slightly positive effect. Use of AAC in secondary settings can support student participation and interaction.

Communication skills increased for all participants and some participants continued communication using tablets after intervention ended and across novel contexts.

From total of 15 studies, 30 out of 31 participants had reported positive results, 1 mixed. Teacher is most common intervention agent and most interventions took place in special education settings.

\section{Recommendations}

Studies need to report more detail on dosage of intervention, specific AAC used, provide data on receptive syntax skills before and after intervention.

Explore use of assistive technology with more varied types and degrees of disability, investigate effective teaching strategies for maintenance and generalization.

Trainers should provide more immediate feedback during intervention. Researchers need to take data on and report procedural integrity.

Researchers should replicate intervention studies with additional participants, increase methodological quality, and report effect sizes.

Future research should investigate using communication apps other than Proloquo2Go and investigate wider range of verbal behaviors as well as device navigation.

Need more information about specific training for interventionists, need more treatment fidelity data reported, need more programming for generalization and maintenance.

Communication addressed in 8 Urgent need for further and reviews: review authors concluded that quality of evidence is low but AAC may be beneficial for individuals with autism. better quality research across different participant demographics and types of AAC

Speech-generating devices $(n=$ Need more research on AAC $4)$ and PECS $(n=3)$ most for individuals with Down frequently used with children with Down syndrome. Both increased communication skills. syndrome and need to measure changes in communication, socialization, language, and motor skills. 
Table 2 (continued)

\begin{tabular}{|c|c|c|c|}
\hline Review & Intervention & Outcomes & Recommendations \\
\hline & $\begin{array}{l}\text { each other types of assistive } \\
\text { technology. }\end{array}$ & & \\
\hline Barker et al., (2012). & $\begin{array}{l}\text { Reading instruction for } \\
\text { children who use AAC. } \\
\text { Total of } 8 \text { studies: } n=5 \\
\text { instruction that directly and } \\
\text { explicitly taught } \\
\text { phonological awareness, } \\
\text { reading, and/or spelling } \\
\text { skills. }\end{array}$ & $\begin{array}{l}\text { Most participants used SGDs } \\
\text { ( } n=16 \text { participants). } \\
\text { Difficult to compare results } \\
\text { due to different measures } \\
\text { and strategies used. }\end{array}$ & $\begin{array}{l}\text { Need standardized assessments } \\
\text { of phonological awareness } \\
\text { and reading that don't } \\
\text { require speech responses, } \\
\text { assess validity of new } \\
\text { assessments, assess validity } \\
\text { of interventions modified to } \\
\text { remove speech elements. }\end{array}$ \\
\hline
\end{tabular}

Barton et al., (2017). Technology-aided intervention and instruction (TAII) for students with autism spectrum disorder (ASD)

Battaglia \& McDonald, PECS for children with ASD (2015).

Biggs et al., (2018).

Aided AAC modeling.

Boyle et al., (2017).

Branson \& Demchak, (2009).

Brunner \& Seung, (2009).

\section{and effects on maladaptive} behavior.

\section{Digital text on}

tablet/computer with visual scene display programmed with hotspots to label pictures. and toddlers with disabilities. Most studies on unaided AAC and $42 \%$ of studies on aided AAC.

Communication treatments for children with ASD. AAC
Computer-aided instruction is an evidence-based practice for students with ASD.

AAC and virtual reality not identified as evidence-based practices.

All participants made gains on proficiency with PECS and increased verbal speech but three out of seven total participants did not demonstrate decreases in maladaptive behavior.

All participants (children and youth with $\mathrm{CCN}$ ) made gains in expressive communication however due to packaged interventions, benefits cannot solely be attributed to aided AAC modeling.

Initial evidence of benefit: increases in communication turns, word learning.

AAC interventions with infants interventions covered were PECS and manual sign.
Improved communication skills for $97 \%$ of participants, communication partners successfully taught to create more opportunities and increase child's use of intentional communication acts.

Manual sign used successfully for longer to teach receptive and expressive vocabulary skills; has strong empirical support. PECS is widely utilized in school settings and across verbal operants.
More research about TAII to determine components, need more research on AAC and virtual reality, specifically group design studies.

Further research on functional relation between PECS use and decrease in maladaptive behavior, researchers should determine function of challenging behavior prior to implementation of PECS.

Further research on aided AAC modeling for older children and adults, more research on focused aided AAC modeling. Study authors should report with greater detail for replicability.

Need more research into how visual scene displays can be used to develop interactive reading interventions. Need research on whether interactive reading between peers and children with disabilities could lead to greater social interactions.

Need more research on comparative effectiveness of various types of AAC for kids with specific disabilities, compare aided vs unaided AAC, investigate use of AAC with infants and toddlers.

Provide more participant information because of heterogeneity of individuals with ASD, have to understand typical interaction/ communication before teaching individuals with ASD. 
Table 2 (continued)

\begin{tabular}{|c|c|}
\hline Review & Intervention \\
\hline Brunner et al., (2017). & $\begin{array}{l}\text { Technology in rehabilitation } \\
\text { for people with traumatic } \\
\text { brain injury. AAC }(n=27) \\
\text { interventions addressed } \\
\text { communication needs, } \\
\text { increasing participation, } \\
\text { improving quality of life. }\end{array}$ \\
\hline
\end{tabular}

Bryant et al., (2010).
Assistive technology as a support for individuals with intellectual disability.

Campbell et al., (2006). Practices for teaching young

Chapin et al., (2018). $\quad$ Peer support for preschoolers

Chung et al., (2012).

Cumming \& Draper Rodriguez (2017).

Desideri et al., (2013).

Assistive technology

Mobile technology supporting to intervention activities used AAC during decrease in challenging behavior, increase in responding and requesting. children (infants and toddlers) to use assistive devices. with ASD. recommendations for children with multiple disabilities. individuals with disabilities.

with complex

communication needs.

AAC helps users communicate and learn new concepts.

One of the included studies addressed AAC: using a

"voice output

communication aid" during snack and play routines. All participants increased communication over baseline.

Children who used AAC prior demonstrated moderate level of effect, children who intervention reported very strong effect. Mostly PECS used $(n=3)$ with only one study with SGD.

Peer training and multicomponent intervention packages are promising interventions for increasing social communication.

Communication skills $(n=7)$ overall indicated a weak effect overall for AAC interventions on communication outcomes.

Overview of models and instruments to guide AT professionals for assessment of children with multiple disabilities.

Paraeducators' results: positive behavior changes reported $(n=7)$, individuals who use AAC: increase in communicative behavior,

Recommendations

Need further research into apps, social media, virtual reality, blogs, more about user perspectives or experiences accessing internet and using mobile devices and apps.

Study authors need to report participant standardized test scores, age, and gender data of participants.

Researchers should provide more information about context of communication device use and teach skills within natural contexts and settings.

Continue research on developmentally appropriate partner training activities, need more research due to small number of studies providing information on peer characteristics.

Investigate peer training as important component, research multicomponent interventions, more research into adult facilitation, research pragmatics, functions, topics of social communication.

Further high quality research in mobile tech and communication. Use greater variety of apps on mobile technology devices (not just Proloquo2Go for communication).

Need to transition from unsystematic experiences and intuitions of clinicians and establish evidence-based practices and need to use validated intervention models and instruments. training for paraeducators to support the communication of individuals who use AAC. review, investigate the
Need more research to strengthen findings of impact of paraprofessionals to support communication and research on how communication partner 
Table 2 (continued)

\begin{tabular}{|c|c|c|}
\hline Review & Intervention & Outcomes \\
\hline Dunst et al. (2013). & $\begin{array}{l}\text { Assistive technology device } \\
\text { use by young children with } \\
\text { disabilities. }\end{array}$ & $\begin{array}{l}\text { All AT device use resulted in } \\
\text { improvements in child } \\
\text { outcomes except } \\
\text { weighted/pressure vests; ef- } \\
\text { fect sizes all very large. }\end{array}$ \\
\hline Erdem (2017). & $\begin{array}{l}\text { Assistive technology for } \\
\text { students with special needs. } \\
\text { Communication: aided and } \\
\text { unaided AAC. }\end{array}$ & $\begin{array}{l}\text { Assistive technology provides } \\
\text { equal educational } \\
\text { opportunities for students } \\
\text { with disabilities and } \\
\text { improve quality of life. }\end{array}$ \\
\hline
\end{tabular}

Recommendations

training impacts individuals who use AAC.

Research on promoting use of assistive technology needs to pay explicit attention paid to differences between implementation and intervention practices.

Researchers should share results of literature reviews at conferences and with teachers, parents, admin, students, assessment of tech, tools, guide materials, teacher training, sample implementations, cooperation among professionals.

Flippin et al., (2010). PECS effectiveness for children with ASD on communication and speech outcomes.

Ganz et al., (2012a). PECS with individuals with ASD

Ganz et al., (2012b). Aided AAC for individuals with $A S D$.

Ganz et al., (2014a). Interaction of participant characteristics and type of AAC.
PECS interventions for children with ASD.

Aided AAC for individuals with ASD.

Comparison of three types of aided AAC: PECS, SGDs, other picture-based.
Speech outcomes varied and mixed, questionable effectiveness for increasing speech. Children who complete Phase IV of PECS higher rates of speech gains. Evidence for maintenance and generalization limited and mixed.

AAC has small to moderate effects on speech outcomes, SGD most effective for ASD without IDD, PECS most effective for ASD and IDD, PECS most effective for preschool. Participants who started with more speech had better speech outcomes, aided AAC doesn't inhibit speech but may enhance.

All participants had moderate or better effects. AAC has small to moderate effects on speech outcomes.

Overall small to moderate positive effects on speech outcomes. SGDs most effective for individuals with ASD, PECS most effective for individuals with ASD and comorbid intellectual and developmental disabilities.

High-tech AAC for individuals with intellectual and
Need to research moderators on effectiveness, why Phase IV results in more speech gains, and what pretreatment characteristics lead to more gains.

Further research into measures of speech outcomes pre/post intervention, report standardized definitions of language levels, report standardized diagnostic measures.

Investigate specific types of AAC with different ages and diagnostic categories. Researchers should provide more information about participants to determine possible mediators (age, severity of disability, level of language skills)

Further research into impacts of SGDs and picture-based AAC on speech outcomes, need to report participants' communication skills from standardized assessments, and report diagnostic information.

Need more research impact of PECS on academic 
Table 2 (continued)

\begin{tabular}{|c|c|c|}
\hline Review & Intervention & Outcomes \\
\hline & $\begin{array}{l}\text { developmental disabilities } \\
\text { and complex } \\
\text { communication needs. }\end{array}$ & $\begin{array}{r}\text { Moderate positive effects of } \\
\text { high-tech AAC on social } \\
\text { communication outcomes }\end{array}$ \\
\hline
\end{tabular}

Ganz et al., (2014b). Moderation of effects of AAC based on setting and types of aided AAC.

Gevarter et al., (2013).

Comparing AAC intervention components for individuals with developmental disabilities. Comparing symbol sets, instructional strategies, speech output in aided AAC, verbal operants in unaided AAC. settings for children with autism spectrum disorder.

Gevarter \& Zamora, (2018).

Gilson et al., (2017).

Methods to teach employment skills to secondary students with intellectual and developmental disabilities.

Hart \& Banda, (2010). $\quad$ PECS with individuals with developmental disabilities.

Heath et al. (2015)
Naturalistic interventions for increasing expressive skills of children who use SGDs in natural contexts.
Aided AAC resulted in the largest effects in general education settings. Both speech-generating devices and PECS had larger effects than other picture-based systems. Speech-generating devices produced larger effects than PECS.

Evidence that PECS acquisition doesn't differ based on use of low and high iconicity symbols, pictures and photographs. Effect of type of speech output on increasing vocalizations were inconclusive.

Mostly positive results (19 of 32 included studies) across variety of types of SGDs, natural change agents as interventionists, peer-mediated interventions successful.

AAC: strong positive effect ( $n$ $=1$ ), mostly positive effects $(n=5)$, no studies with mixed effect or no effect included.

PECS interventions resulted in increases in functional communication in all but 1 participant, decreased problem behavior, increased vocal verbal speech in some participants.

ighest gains for verbal individuals, then aided AAC, then unaided AAC. Highest gains for ASD
Recommendations

performance, utility of speech-generating devices and other picture based AAC to improve social skills, component analysis of aided AAC when part of intervention package.

Need research on the effects of AAC on skills other than communication, investigate instructional elements of $\mathrm{AAC}$ interventions to find most effective, different types of symbols on behavioral objectives.

More research into differences based on iconicity and receptive learning, compare different symbol sets and SGD-based comparisons. Need more research on whether presence/absence of speech output, type (digitized or synthesized), long or short output influences $\mathrm{AAC}$ acquisition.

Strategies and intervention procedures should be individualized, further research into interventions for individuals with ASD, research with individuals with multiple disabilities, component analysis of strategies.

Need to target social skills in employment interventions. Need more research to support more legislation to create opportunities for adults with disabilities and need more research with participants with severe disabilities.

Researchers should investigate completing formal preference and reinforcer assessments before conducting intervention studies. Need research into how manipulating symbol, referent and instructional variables affects acquisition of pictures during training.

Research to determine cognitive ability or communicative ability impact on FCT, secondary 
Table 2 (continued)

\begin{tabular}{|c|c|c|c|}
\hline Review & Intervention & Outcomes & Recommendations \\
\hline & & $\begin{array}{l}\text { compared to ID. FCT is } \\
\text { evidence based practice for } \\
\text { ASD. }\end{array}$ & $\begin{array}{l}\text { age participants, component } \\
\text { analysis, brief FAs vs FAs } \\
\text { and FBA, generalization } \\
\text { and maintenance data } \\
\text { needed }\end{array}$ \\
\hline
\end{tabular}
Holyfield et al., (2017). $\quad \begin{aligned} & \text { AAC interventions for } \\ & \text { adolescents and adults with } \\ & \text { ASD. }\end{aligned}$

Hong et al., (2017).

Iacono et al., (2016).

Kagohara et al., (2013). Mobile tablets as communication devices for children with developmental disabilities.

Kent-Walsh et al., (2015).

Kim \& Kimm, (2017). Mobile device-based technology for individuals with intellectual disabilities. Video prompting, video self-prompting, video modeling, picture prompting, systematic instruction with device, speech-generating app.
Very large effect size for effect More intervention research for of AAC interventions on targeted behaviors for adolescents and adults with ASD.

Tablet-mediated interventions for individuals with ASD have overall large effects across all age groups for social and communication outcomes. older children and adults with ASD, studies need to have higher methodological rigor, and more research focusing on social interaction.

Need additional research on tablet-mediated interventions' effect on academic skills, life skills, community access, household chores, school readiness.

Included reviews favored aided Researchers and review authors AAC. Most evidence supports PECS and SGD in interventions, manual sign only used to compare to aided systems. Most research on teaching FCT and focuses on requests. Most research on efficacy of PECS for kids with ASD. should provide details of participant characteristics including communication skills of participants at start of intervention, research AAC interventions on more functions than requests, do research in real world environments, and address needs of children with severe and complex disabilities.

Participants requested preferred Mobile devices (iPads, iPods, stimuli (food, items) by selecting icons via apps installed on mobile touchscreen tablets. iPhones) can successfully be used by individuals with developmental disabilities; expand communication functions beyond requesting and naming preferred stimuli, assess social validity as SGDs.

Communication partner instruction within AAC interventions has positive effects on communication skills of individuals using AAC. Most frequently targeted strategies are aided AAC modeling, expectant delay, and open-ended question asking.

Mobile device-based intervention very effective for individuals with intellectual disabilities, effect sizes did not significantly differ across target skill domains.
Need to support and teach communication partners within educational, medical, and private sector service delivery settings, and integrate communication partner instruction in preservice personnel preparation programs.

Research on effectiveness of mobile devices in various settings and functions beyond instructional in the classroom is in beginning stages: researchers and practitioners should use functional technology in daily activities to improve 
Table 2 (continued)

\begin{tabular}{llcc}
\hline Review & Intervention & Outcomes & Recommendations \\
\hline Lancioni et al. (2007). & $\begin{array}{c}\text { PECS and "voice output } \\
\text { communication aids" } \\
\text { interventions' effects on } \\
\text { requesting by students with } \\
\text { developmental disabilities. }\end{array}$ & $\begin{array}{c}\text { Most participants who used } \\
\text { PECS and speech output } \\
\text { devices gained } \\
\text { communication skills and } \\
\text { successfully learned to } \\
\text { make requests. }\end{array}$ & $\begin{array}{c}\text { Further research into individual } \\
\text { preference for type of AAC } \\
\text { and impact on use of AAC } \\
\text { and benefits of either type } \\
\text { of AAC on speech } \\
\text { development. }\end{array}$
\end{tabular}

Lancioni et al., (2001). Microswitches and speech

Logan et al., (2017). output systems with individuals with intellectual or multiple disabilities.

\section{Aided AAC to increase} social-communication skills in children with ASD, focusing on communicative functions other than requesting.

Positive and mixed findings. Speech output resulted in more expressive communication, usually with one communication modality, most often requesting.

Emerging evidence that AAC interventions can be used to teach variety of communication functions to children with ASD other than object requests.
Lorah et al., (2015).

Tablets and portable media
players as SGDs for
individuals with ASD.

Lynch et al., (2018).

Machalicek et al., (2010)
Interventions to support graphic symbol learning and aided language development by children who use aided AAC.

Literacy interventions for students with physical and developmental disabilities who use aided AAC.
Promising evidence for mobile technology as AAC but tablets only compared so far. Most studies used one app on mobile tablets. Most participants prefer tablet over manual sign or PECS.

Aided AAC modeling can be considered an

evidence-based practice.

Also there is strong research evidence to support use of narrative-based interventions and mand-model procedures to facilitate graphic symbol learning and language acquisition.

Systematic instruction was most effective to increase literacy skills and increase participation in literacy activities. Outcomes mostly positive for all studies and if literacy skills didn't increase, communication skills did improve.

All included studies were successful in reducing
Need research on strategies to introduce microswitch to individuals with severe disabilities and ways to integrate switch use into daily routines and activities.

Included studies did not address generalization, maintenance, or social validity of interventions. Future research on communication functions other than requesting is needed and whether intervention effects are sustained over time.

Need research into how AAC can grow with individual, research app interface design, user interaction, user experience, research into creating training protocols on how to learn different functions of communication, and how to program and use devices.

Researchers should compare effectiveness of instructional strategies at different stages of aided language acquisition and use consistent terminology across research literature.

Researchers should conduct more rigorous experimental designs, component analysis of packages to determine individual instructional components effectiveness, and evaluate general education teachers' delivery of literacy instruction to students included in general education classrooms.

Researchers should use natural opportunities (e.g., lunch 
Table 2 (continued)

\begin{tabular}{lll}
\hline Review & Intervention & Outcomes \\
\hline $\begin{array}{c}\text { Functional communication } \\
\text { training interventions for } \\
\text { children with ASD. }\end{array}$ & $\begin{array}{l}\text { challenging behavior and } \\
\text { increasing communication } \\
\text { but communication mands } \\
\text { limited in scope (e.g. taught }\end{array}$ \\
& a single mand).
\end{tabular}

Millar et al., (2006).

AAC interventions' impact on speech production of individuals with developmental disabilities.

Morin et al., (2018).

Muharib et al. (2018).

Murray et al., (2014).

Nam et al., (2018).

O’Neill et al., (2018).
High tech AAC interventions.

High-tech speech-generating devices as an evidence-based practice for children with ASD.

AAC systems' impact on communicative effectiveness in children with severe childhood

Overview of reviews on interventions using popular AAC systems with individuals with developmental disabilities.

AAC interventions for individuals with $\mathrm{CCN}$. apraxia of speech.
Recommendations

time, routines in classroom) during interventions and train natural change agents.

Researchers should investigate effects of aided AAC on speech production for children and adults with developmental disabilities, what factors may best predict gains in speech production, and determine comparative effectiveness and efficiency of interventions to promote speech production.

Researchers should increase methodological rigor when designing and implementing single case research designs, investigate communication functions than requesting, and conduct interventions in natural settings.

High-tech SGD interventions have large effects on manding, intraverbals, multi-step tacting skills with children with ASD.

Need more research on interventions in natural environments, using natural communication partners, programming for generalization, communication functions other than manding.

Participants used AAC to alleviate frustration and behavior problems due to communication failure. Aided AAC most effective intervention.

Future research should compare treatment approaches, should program for generalization and assess maintenance, and compare whether AAC interventions can promote speech gains over speech-based interventions.

Positive effects of using iPads as AAC for individuals with limited speech such as improved communication skills.

Future research should evaluate and assess preferred type of AAC for each child and conduct more focused analyses to decrease heterogeneity of participants, designs, and outcomes

Interventions using aided AAC Need further research on input were highly effective long-term outcomes of across participants and language skills. interventions, older participants, effects on comprehension skills, partner use on communication outcomes. 
Table 2 (continued)

\begin{tabular}{llcl}
\hline Review & Intervention & Outcomes & Recommendations \\
\hline Odom et al., (2015). & $\begin{array}{c}\text { Technology-aided } \\
\text { interventions for } \\
\text { adolescents with ASD. }\end{array}$ & $\begin{array}{c}\text { Mobile tech as } \\
\text { speech-generating device } \\
\text { increased communication } \\
\text { skills for participants in } \\
\text { school setting }(n=1) .\end{array}$ & $\begin{array}{c}\text { Need more research in } \\
\text { communication with } \\
\text { technology for adolescents } \\
\text { with ASD and possible } \\
\text { negative effects of } \\
\text { technology use. }\end{array}$
\end{tabular}

Ok, (2018).

Ostryn et al., (2008).

PECS for individuals with ASD.

Østvik et al., (2017).

Friendship between children who use $\mathrm{AAC}$ and peers.

Pinto et al., (2009).

Preston \& Carter, (2009).

Ramdoss et al., (2011). Computer-based interventions to deliver instruction on speech and language interventions to children with $\operatorname{ASD}(n=4)$.

PECS
Use of iPads as AAC may be due to lower price compared to other speech-generating devices.

Positive outcomes for individuals with ASD, particularly with manding and generalizing manding.

Children who use AAC have fewer friends and acquaintance: Their parents' friends are their friends. Close family members are preferred communication partners. Conversations are limited by vocabulary on SGDs, delayed communication, poor output volume, or poor voice quality.

Individuals with severe disabilities can effectively communicate using symbolic or idiosyncratic communication forms.

Preliminary evidence that PECS is readily learned by most participants with positive effects on social-communication and challenging behavior. Effects on speech dev unclear. Most participants mastered at least Phase I of PECS.

Limited evidence to support use of computer-based interventions: few studies and small number of participants, but some improvement in communication.
Need more research to replicate effects of using iPads as assistive technology and conduct research with populations other than individuals with developmental disabilities.

Researchers should program for generalization from the beginning of intervention, re-evaluate vocabulary and icons because individual needs change over time.

Further research on indicators of social relationships, different types of relationships, characteristics of friendships, models of friendship development, characteristics of friendships at different ages/stages of development, how children who use AAC establish friendships, and reciprocity in friendships between children with AAC and peers.

Researchers need to increase programming for generalization and maintenance of outcomes, involve natural change agents such as teachers and parents, increase reporting of treatment integrity, and conduct research in natural contexts.

Further research on component analysis of PECS, compare to other AAC interventions, and studies should have higher methodological rigor to contribute to establishing evidence-based practices.

Researchers should design interventions to promote generalization across natural settings and natural consequences, investigate prerequisite skills to use technology, and conduct 
Table 2 (continued)

\begin{tabular}{|c|c|c|}
\hline Review & Intervention & Outcomes \\
\hline Rispoli et al., (2010). & $\begin{array}{l}\text { Speech-generating devices in } \\
\text { communication } \\
\text { interventions for individuals } \\
\text { with developmental } \\
\text { disabilities. }\end{array}$ & $\begin{array}{l}\text { Mostly positive outcomes } \\
\text { ( } 86 \% \text { of included studies), } \\
54 \% \text { studies provide } \\
\text { conclusive evidence. } \\
\text { Evidence base is promising. }\end{array}$ \\
\hline Roche et al., (2014). & $\begin{array}{l}\text { Tangible symbols as AAC } \\
\text { option (e.g. 3D whole } \\
\text { objects or partial objects } \\
\text { created uniquely and } \\
\text { individualized for the study) } \\
\text { for individuals with } \\
\text { developmental disabilities. }\end{array}$ & $\begin{array}{l}\text { Symbols mostly taught to } \\
\text { facilitate requesting, } \\
\text { participants learned to use } \\
\text { tangible symbols to } \\
\text { communicate ( } 54 \% \text { of } \\
\text { participants). Tangible } \\
\text { symbol use is promising } \\
\text { practice. }\end{array}$ \\
\hline
\end{tabular}

Recommendations

more research with individuals with severe autism.

Researchers should replicate findings with additional participants, investigate communication functions other than requesting, and conduct group design studies.

Researchers should evaluate effects of symbol iconicity, realism, and concreteness on intervention outcomes; compare advantages and disadvantages of using standardized or individualized symbols; and whether tangible symbols are learned faster, maintained better, and preferred over other AAC.

Roche et al., (2015). Microswitches for self-enabling responding in children with profound and multiple disabilities.

Positive results for children for accessing preferred stimuli, for making choices, gaining attention/social interaction. Overall positive results and every participant learned to activate microswitches.

Overall increase in number of studies, positive effects of early AAC interventions on communication, language and speech outcomes.
Schlosser \& Wendt, (2008).
AAC interventions effects on speech production of children with ASD.
Schlosser \& Blischak, Role of speech output from (2001).
AAC systems and benefits for people with ASD.
AAC does not impede speech production or result in a decline in speech production. Intervention results in modest gains.

Few studies with speech output as an independent variable. Synthetic speech doesn't have intonation or prosody but might be more helpful for listeners with ASD compared to natural speech.
Researchers should investigate use of microswitches for more functions, compare different types, replicate studies by other teams, research into whether children with profound/multiple disabilities could learn to use emerging new tech (e.g. eye gaze control of computers).

Researchers should replicate studies with children with different diagnoses/disabilities, include families in intervention development, impact of multiple languages and cultures, assess long-term outcomes of interventions, study integration of current and future technology.

Research hypotheses for why SGD may facilitate natural speech and research whether there is a causal relation between AAC interventions and speech production.

Need more studies to investigate synthetic speech as receptive AAC method, investigate digitized speech, investigate whether speech output could support other 
Table 2 (continued)

\begin{tabular}{lll}
\hline Review & Intervention & Outcomes
\end{tabular}

Schlosser et al., (2014). Facilitated communication

Sennott et al., (2016).

AAC modeling in naturalistic

Shire \& Jones, (2015).

Sievers et al., (2018).

Smith \& Iadarola, (2015).

Snell et al., (2006). (FC) position statement. communication interactions.
Communication partner interventions for partners of

Evidence base update for ASD. Communication outcomes: individual focused applied behavior analysis-based interventions with AAC.

Child-related factors impacting intervention effectiveness for AAC outcomes for children with ASD. children who use AAC.

Messages generated through FC are authored by the facilitator and not the individual with disabilities. FC has no validity. Outcomes support assumption of facilitator influence.

Large changes in communication performance from baseline. Gains in receptive and expressive language skills. Recommend using AAC modeling as foundation of AAC intervention.

Large effects and positive findings for partner skills and children's communication that maintained over time. Most 11 studies examined aided $\operatorname{AAC}(n=11)$.

Child characteristics include pre-intervention cognition, severity of ASD, verbal imitation skills, vocabulary comprehension, object use. Emerging evidence for predictors.

\section{PECS and SGDs have} evidence to support positive effects. Applied behavior analysis-focused AAC is probably efficacious (needs more group design and longer follow up). Use of picture symbols to make requests was most frequently reported outcome. treatment methods (e.g. spoken prompt).

$\mathrm{FC}$ is not an EBP or valid method for communication.

Researchers should expand participant population, more contexts of intervention, research across lifespan, include adults who may have acquired disabilities later in life, and research across more communication domains.

Researchers should clearly delineate instructional strategies to communication partners and report child communication initiations and responses.

Need more research on mediators of AAC intervention effectiveness, need high quality research designs to determine causality, researchers should make datasets more readily available for statistical analyses.

Need more research on mediators and moderators of individualized, comprehensive interventions, having standardized outcome measures would help with treatment comparisons, develop a standard for reporting study procedures, and develop a standardized effect size reporting and quality of evidence measures.

More research on natural communication partners: peers/siblings and less adults, role of partner, conduct component analysis of interventions, report treatment integrity, examine effects of treatment 
Table 2 (continued)

$\begin{array}{lll}\text { Review Intervention } & \text { Outcomes } & \text { Recommendations }\end{array}$

Stauter et al., (2017).

Literacy instruction: Modeling AAC use, adapting materials, subvocal rehearsal of words, contextual learning, and differentiated instruction.
Stephenson \& Limbrick, Touchscreen mobile devices (2015).

Still et al., (2014).

Sulzer-Azaroff et al., (2009).

Therrien et al., (2016). with people with developmental disabilities.

High-tech AAC to teach functional requesting skills.

PECS: Whether PECS enables nonspeaking participants to initiate functional communication, tested adaptations due to mobility needs, made icon 3D, tactile for vision impaired, compare to other interventions.

Interventions to promote peer interactions with children who use aided AAC. Most frequently used: teaching children with $\mathrm{CCN}$ how to use AAC within social interactions and teaching peers skills and strategies to promote interaction.
AAC in inclusive settings increases children's participation and engagement, children demonstrated preferences for adapted materials/books. intensity/dosage, and assess students' entry skill level.

Research emergent literacy development for young children under 3 , measure secondary measures (children motivation and participation, teacher expectations, teacher perceptions about intervention feasibility), report information about home and social environment, report follow-up, clear definition of emergent literacy outcomes, and conduct studies with larger sample sizes.

Very large positive effects for communication with mobile touchscreen devices (e.g. iPod touch).

Communication studies used 3 apps: Proloquo2Go, Pick a Word, Pixtalk and focused on requesting. Some participants learned to activate device, navigate across pages, make a choice, and name pictures.

SGDs most often used, most frequent targets were requesting food or toys, overall largely positive results. Dedicated SGD used more frequently than tablet-based apps.

Improvement in communication for participants who used skills with teachers and caregivers. Participants preferred using PECS. PECS intervention outcomes: resulted in increased speaking and social approaching, decreases in disruptive or dangerous bx.

Positive effects on interactions with peers, although results varied: Older participants had higher effect sizes than younger, more gains in peer communicative interactions, frequency of initiations, and frequency of communicative acts.
Researchers should investigate more apps, effectiveness of dedicated device compared to app, younger participants need to be included, and research how people with disabilities are using devices and apps outside of formal intervention settings.

Researchers should conduct more empirical research across range of skills, academic skills, requesting info, conversation skills, and the impact of feedback on correct responding.

Researchers should record dates, times, settings, personnel, and materials as well as correct/incorrect responses during intervention, increase opportunities to promote generalization.

Researchers should conduct more studies on children with ASD, compare effects of two different interventions, component analyses, training paraprofessionals as facilitators of peer interaction, and identify variables that distinguish 
Table 2 (continued)

\begin{tabular}{|c|c|c|c|}
\hline Review & Intervention & Outcomes & Recommendations \\
\hline & & & $\begin{array}{l}\text { friendship from } \\
\text { acquaintance. }\end{array}$ \\
\hline Tien, (2008). & $\begin{array}{l}\text { PECS as FCT for individuals } \\
\text { with ASD. }\end{array}$ & $\begin{array}{l}\text { PECS is effective for } \\
\text { improving functional } \\
\text { communication skills, } \\
\text { increasing spontaneous } \\
\text { communication, and } \\
\text { increase in mean length of } \\
\text { utterances. }\end{array}$ & $\begin{array}{l}\text { Further research with } \\
\text { individuals with other } \\
\text { diagnoses/disabilities. }\end{array}$ \\
\hline Tincani \& Devis, (2011) & PECS & $\begin{array}{l}\text { PECS is moderately effective } \\
\text { in establishing mands up to } \\
\text { Phase IV. Higher levels of } \\
\text { manding found when PECS } \\
\text { taught to individuals } \\
\text { without ASD. For small } \\
\text { subset of participants, } \\
\text { PECS appears to facilitate } \\
\text { speech. }\end{array}$ & $\begin{array}{l}\text { Need more research to } \\
\text { establish efficacy of later } \\
\text { phases of PECS (most } \\
\text { stopped at Phase III), } \\
\text { replicate operational } \\
\text { definitions and settings of } \\
\text { current studies due to } \\
\text { variability in speech } \\
\text { definitions and outcome } \\
\text { measured, and increase use } \\
\text { of natural change agents. }\end{array}$ \\
\hline $\begin{array}{l}\text { Van Der Meer \& } \\
\text { Rispoli. (2010). }\end{array}$ & $\begin{array}{l}\text { SGD interventions for children } \\
\text { with ASD. }\end{array}$ & $\begin{array}{l}\text { Overall positive outcomes: } \\
87 \% \text { positive outcomes, } \\
13 \% \text { mixed outcomes, no } \\
\text { negative outcomes reported. } \\
\text { Most studies investigated } \\
\text { requesting, used behavioral } \\
\text { strategies, and were } \\
\text { conducted in school } \\
\text { settings. }\end{array}$ & $\begin{array}{l}\text { Future research should } \\
\text { investigate teaching skills } \\
\text { other than requesting, child } \\
\text { preference for different } \\
\text { AAC systems, and } \\
\text { determining differential } \\
\text { effects of discrete trial } \\
\text { training compared to } \\
\text { naturalistic interventions. }\end{array}$ \\
\hline $\begin{array}{l}\text { Van der Meer et al., } \\
\text { (2011). }\end{array}$ & $\begin{array}{l}\text { Preferences for AAC options in } \\
\text { communication } \\
\text { interventions by individuals } \\
\text { with developmental } \\
\text { disabilities. }\end{array}$ & $\begin{array}{l}67 \% \text { of participants had some } \\
\text { degree of preference for } \\
\text { using SGD compared to } \\
33 \% \text { participants' } \\
\text { preference for picture } \\
\text { exchange. }\end{array}$ & $\begin{array}{l}\text { Research participant preference } \\
\text { for different AAC options } \\
\text { and whether preferences } \\
\text { generalize across situations } \\
\text { and communicative } \\
\text { partners. }\end{array}$ \\
\hline Walker \& Snell, (2013). & $\begin{array}{l}\text { Effectiveness of AAC } \\
\text { interventions on } \\
\text { challenging behavior of } \\
\text { individuals with disabilities. }\end{array}$ & $\begin{array}{l}\text { AAC intervention has positive } \\
\text { moderate effects on } \\
\text { decreasing CB for } \\
\text { individuals with varying } \\
\text { disabilities. }\end{array}$ & $\begin{array}{l}\text { Need additional research on } \\
\text { teaching typical } \\
\text { interventionists to conduct } \\
\text { functional behavior } \\
\text { assessments and increase } \\
\text { social validity data and } \\
\text { reporting. }\end{array}$ \\
\hline Walker et al., (2018). & $\begin{array}{l}\text { Functional communication } \\
\text { training (FCT) implemented } \\
\text { in schools with children } \\
\text { who use AAC. }\end{array}$ & $\begin{array}{l}\text { AAC interventions using FCT } \\
\text { were effective in reducing } \\
\text { challenging behavior and } \\
\text { promoting aided or unaided } \\
\text { AAC use. }\end{array}$ & $\begin{array}{l}\text { Researchers should make sure } \\
\text { behavior change maintains } \\
\text { over time and specific } \\
\text { instructional procedures to } \\
\text { provide guidelines for } \\
\text { practitioners. }\end{array}$ \\
\hline
\end{tabular}

intellectual and developmental disabilities who have complex communication needs. Data from this overview of research literature indicate that review methodological quality is improving slightly over time. Most of the research used single-case research designs, utilized behavioral interventions, was conducted with participants using a speech-generating device, was conducted with children diagnosed with autism spectrum disorder ages 5-18 in general education settings, and is most frequently synthesized in systematic reviews of literature. 
AMSTAR 2 Percentages by Publication Year

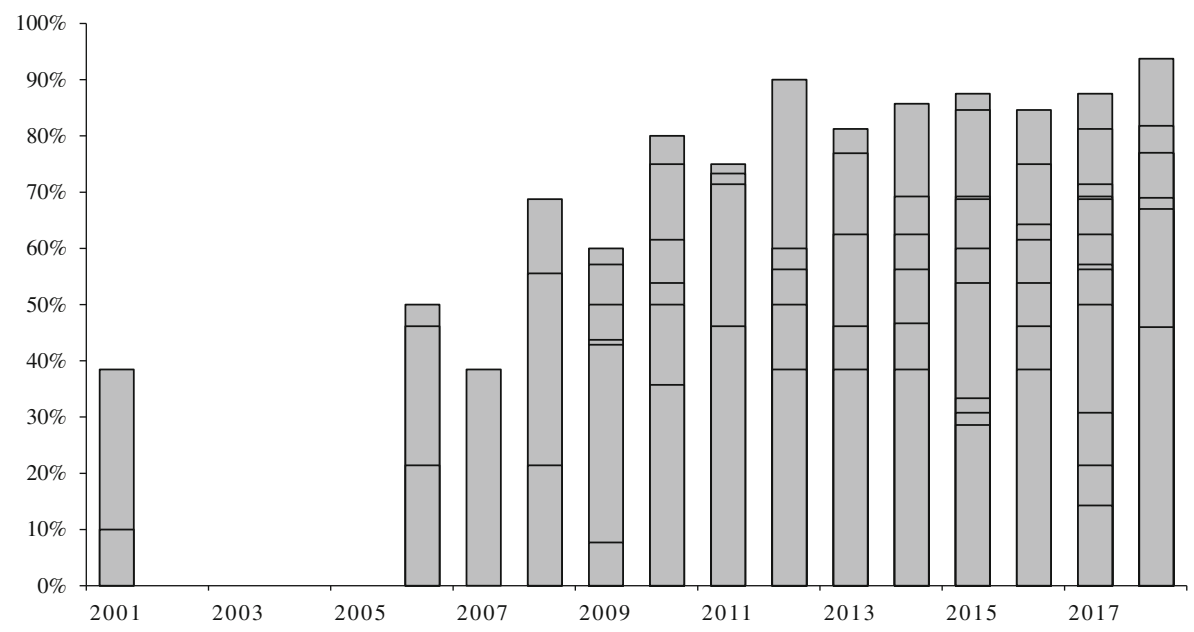

Fig. 2 AMSTAR 2 scores in chronological order by publication year. Each review's AMSTAR 2\% achieved is indicated by sections within each publication year bar

\section{Thematic Issues Raised by Reviews as Areas of Need in Aided AAC Research}

Assessing and reporting pre-intervention communication skills, particularly vocal communication skills (Walker et al., 2018), intervening on younger children rather than waiting for natural speech before beginning AAC interventions (Alper \&

Table 3 Percent of Reviews Scoring Yes or Partial Yes for Each AMSTAR 2 Indicator

\begin{tabular}{lll}
\hline Item & Indicator & Percent of reviews \\
\hline 1 & Research question and inclusion criteria a priori & 85 \\
2 & Explicit statement of methods protocol & 90 \\
3 & Explain selection of studies for inclusion & 93 \\
4 & Comprehensive literature search & 92 \\
5 & Study selection in duplicate & 50 \\
6 & Data extraction in duplicate & 63 \\
7 & List of excluded studies and why excluded & 5 \\
8 & Adequate detail of included studies & 89 \\
9 & Assess study risk of bias & 15 \\
10 & Report study sources of funding & 1 \\
11 & Meta analysis: appropriate statistics & 33 \\
12 & Meta analysis: assess risk of bias of results & 27 \\
13 & Risk of bias individual studies interpretation & 26 \\
14 & Explain heterogeneity in results & 25 \\
15 & Quantitative investigation of publication bias & 1 \\
16 & Report review conflict of interests and funding & 44 \\
\hline
\end{tabular}

Note. Percent of reviews calculated by the total number of reviews with "Yes" or "Partial Yes" for that item divided by 84 total reviews. 
Table 4 AMSTAR 2 Scores by Each Included Review

Review

AMSTAR 2 Items

Percent

$\begin{array}{llllllllllllllll}1 & 2 & 3 & 4 & 5 & 6 & 7 & 8 & 9 & 10 & 11 & 12 & 13 & 14 & 15 & 16\end{array}$

Allen et al., (2017).

$\begin{array}{lllllllllllllllll}\mathrm{Y} & \mathrm{Y} & \mathrm{Y} & \mathrm{Y} & \mathrm{N} & \mathrm{Y} & \mathrm{N} & \mathrm{N} & \mathrm{N} & \mathrm{N} & \mathrm{Y} & \mathrm{N} & \mathrm{N} & \mathrm{Y} & \mathrm{N} & \mathrm{Y} & 50 \%\end{array}$

Alper \& Raharinirina, $\begin{array}{lllllllllllllllll}\mathrm{Y} & \mathrm{N} & \mathrm{N} & \mathrm{N} & \mathrm{N} & \mathrm{Y} & \mathrm{N} & \mathrm{Y} & \mathrm{N} & \mathrm{N} & \mathrm{n} / \mathrm{a} & \mathrm{n} / \mathrm{a} & \mathrm{N} & \mathrm{N} & \mathrm{N} & \mathrm{N} & 21 \%\end{array}$ (2006).

$\begin{array}{llllllllllllllllll}\text { Alsayedhassan et al. (2016). } & \mathrm{Y} & \mathrm{Y} & \mathrm{Y} & \mathrm{Y} & \mathrm{Y} & \mathrm{N} & \mathrm{N} & \mathrm{Y} & \mathrm{N} & \mathrm{N} & \mathrm{n} / \mathrm{a} & \mathrm{n} / \mathrm{a} & \mathrm{N} & \mathrm{N} & \mathrm{n} / \mathrm{a} & \mathrm{N} & 46 \%\end{array}$ $\begin{array}{llllllllllllllllllll}\text { Alwell \& Cobb, (2009). } & \mathrm{Y} & \mathrm{Y} & \mathrm{Y} & \mathrm{Y} & \mathrm{N} & \mathrm{Y} & \mathrm{N} & \mathrm{Y} & \mathrm{N} & \mathrm{N} & \mathrm{Y} & \mathrm{N} & \mathrm{N} & \mathrm{N} & \mathrm{N} & \mathrm{N} & 44 \%\end{array}$ $\begin{array}{lllllllllllllllllll}\text { Alzrayer et al., (2014). } & \text { Y } & \text { Y } & \text { Y } & \text { Y } & \text { Y } & \text { N } & \text { N } & \text { Y } & \text { N } & \text { N } & \text { Y } & \text { Y } & \text { N } & \text { N } & \text { n/a } & \text { N } & 47 \%\end{array}$ $\begin{array}{llllllllllllllllll}\text { Andzik et al., (2016). } & \mathrm{Y} & \mathrm{Y} & \mathrm{Y} & \mathrm{Y} & \mathrm{N} & \mathrm{Y} & \mathrm{N} & \mathrm{Y} & \mathrm{N} & \mathrm{N} & \mathrm{n} / \mathrm{a} & \mathrm{n} / \mathrm{a} & \mathrm{Y} & \mathrm{N} & \mathrm{N} & \mathrm{Y} & 64 \%\end{array}$ $\begin{array}{lllllllllllllllllll}\text { Anttila et al., (2012). } & \mathrm{Y} & \mathrm{Y} & \mathrm{Y} & \mathrm{Y} & \mathrm{N} & \mathrm{Y} & \mathrm{N} & \mathrm{Y} & \mathrm{N} & \mathrm{N} & \mathrm{n} / \mathrm{a} & \mathrm{n} / \mathrm{a} & \mathrm{N} & \mathrm{N} & \mathrm{N} & \mathrm{Y} & 50 \%\end{array}$ $\begin{array}{llllllllllllllllll}\text { de Barbosa et al., (2018). } & \text { Y } & Y & Y & Y & Y & Y & N & Y & n / a & Y & \text { n/a } & \text { n/a } & \text { n/a } & \text { n/a } & \text { n/a } & \text { Y } & 82 \%\end{array}$ $\begin{array}{llllllllllllllllll}\text { Barker et al., (2012). } & \text { Y } & Y & Y & Y & N & N & N & Y & N & N & n / a & n / a & N & N & N & Y & 50 \%\end{array}$ Barton et al., (2017). $\begin{array}{lllllllllllllllll}\mathrm{Y} & \mathrm{Y} & \mathrm{Y} & \mathrm{Y} & \mathrm{Y} & \mathrm{Y} & \mathrm{N} & \mathrm{Y} & \mathrm{Y} & \mathrm{N} & \mathrm{Y} & \mathrm{Y} & \mathrm{Y} & \mathrm{Y} & \mathrm{N} & \mathrm{Y} & 88 \%\end{array}$

Battaglia \& McDonald, (2015).

Biggs et al., (2018). $\begin{array}{lllllllllllllllll}\mathrm{Y} & \mathrm{Y} & \mathrm{Y} & \mathrm{Y} & \mathrm{N} & \mathrm{N} & \mathrm{N} & \mathrm{N} & \mathrm{N} & \mathrm{N} & \mathrm{n} / \mathrm{a} & \mathrm{n} / \mathrm{a} & \mathrm{N} & \mathrm{N} & \mathrm{N} & \mathrm{N} & 29 \%\end{array}$

Boyle et al., (2017).

$\begin{array}{lllllllllllllllll}\mathrm{Y} & \mathrm{Y} & \mathrm{Y} & \mathrm{Y} & \mathrm{Y} & \mathrm{Y} & \mathrm{N} & \mathrm{Y} & \mathrm{Y} & \mathrm{N} & \mathrm{n} / \mathrm{a} & \mathrm{n} / \mathrm{a} & \mathrm{N} & \mathrm{Y} & \mathrm{n} / \mathrm{a} & \mathrm{Y} & 77 \%\end{array}$

Branson \& Demchak, (2009).

Brunner \& Seung, (2009). Brunner et al., (2017).

$\begin{array}{lllllllllllllllll}\mathrm{N} & \mathrm{N} & \mathrm{N} & \mathrm{N} & \mathrm{N} & \mathrm{N} & \mathrm{N} & \mathrm{N} & \mathrm{N} & \mathrm{N} & \mathrm{n} / \mathrm{a} & \mathrm{n} / \mathrm{a} & \mathrm{N} & \mathrm{N} & \mathrm{N} & \mathrm{Y} & 14 \%\end{array}$ $\begin{array}{lllllllllllllllll}\mathrm{N} & \mathrm{Y} & \mathrm{Y} & \mathrm{Y} & \mathrm{Y} & \mathrm{Y} & \mathrm{N} & \mathrm{Y} & \mathrm{N} & \mathrm{N} & \mathrm{Y} & \mathrm{n} / \mathrm{a} & \mathrm{n} / \mathrm{a} & \mathrm{N} & \mathrm{N} & \mathrm{N} & 50 \%\end{array}$

Bryant et al., (2010).

$\begin{array}{lllllllllllllllll}\mathrm{N} & \mathrm{Y} & \mathrm{Y} & \mathrm{Y} & \mathrm{N} & \mathrm{N} & \mathrm{N} & \mathrm{Y} & \mathrm{N} & \mathrm{N} & \mathrm{n} / \mathrm{a} & \mathrm{n} / \mathrm{a} & \mathrm{N} & \mathrm{N} & \mathrm{N} & \mathrm{Y} & 43 \%\end{array}$

Campbell et al., (2006).

$\begin{array}{lllllllllllllllll}\mathrm{Y} & \mathrm{Y} & \mathrm{Y} & \mathrm{N} & \mathrm{N} & \mathrm{N} & \mathrm{N} & \mathrm{N} & \mathrm{N} & \mathrm{N} & \mathrm{n} / \mathrm{a} & \mathrm{n} / \mathrm{a} & \mathrm{N} & \mathrm{N} & \mathrm{N} & \mathrm{N} & 21 \%\end{array}$

Chapin et al., (2018).

$\begin{array}{lllllllllllllllll}\mathrm{Y} & \mathrm{Y} & \mathrm{N} & \mathrm{Y} & \mathrm{N} & \mathrm{N} & \mathrm{Y} & \mathrm{Y} & \mathrm{N} & \mathrm{N} & \mathrm{n} / \mathrm{a} & \mathrm{n} / \mathrm{a} & \mathrm{N} & \mathrm{N} & \mathrm{N} & \mathrm{N} & 36 \%\end{array}$

$\begin{array}{lllllllllllllllll}\mathrm{Y} & \mathrm{Y} & \mathrm{Y} & \mathrm{Y} & \mathrm{N} & \mathrm{Y} & \mathrm{Y} & \mathrm{n} / \mathrm{a} & \mathrm{N} & \mathrm{N} & \mathrm{n} / \mathrm{a} & \mathrm{n} / \mathrm{a} & \mathrm{N} & \mathrm{N} & \mathrm{n} / \mathrm{a} & \mathrm{N} & 50 \%\end{array}$

Chung et al., (2012).

$\begin{array}{lllllllllllllllll}\mathrm{Y} & \mathrm{Y} & \mathrm{Y} & \mathrm{Y} & \mathrm{Y} & \mathrm{Y} & \mathrm{N} & \mathrm{Y} & \mathrm{N} & \mathrm{N} & \mathrm{n} / \mathrm{a} & \mathrm{n} / \mathrm{a} & \mathrm{N} & \mathrm{Y} & \mathrm{n} / \mathrm{a} & \mathrm{Y} & 69 \%\end{array}$

$\begin{array}{lllllllllllllllll}\mathrm{Y} & \mathrm{Y} & \mathrm{Y} & \mathrm{Y} & \mathrm{Y} & \mathrm{Y} & \mathrm{N} & \mathrm{Y} & \mathrm{N} & \mathrm{N} & \mathrm{n} / \mathrm{a} & \mathrm{n} / \mathrm{a} & \mathrm{N} & \mathrm{N} & \mathrm{N} & \mathrm{Y} & 90 \%\end{array}$

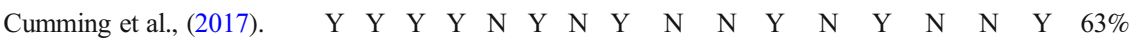

$\begin{array}{lllllllllllllllllllllll}\text { Desideri et al., (2013). } & \mathrm{N} & \mathrm{Y} & \mathrm{Y} & \mathrm{Y} & \mathrm{N} & \mathrm{Y} & \mathrm{N} & \mathrm{Y} & \mathrm{N} & \mathrm{N} & \mathrm{n} / \mathrm{a} & \mathrm{n} / \mathrm{a} & \mathrm{N} & \mathrm{N} & \mathrm{n} / \mathrm{a} & \mathrm{N} & 38 \%\end{array}$

$\begin{array}{llllllllllllllllll}\text { Douglas, (2012). } & \mathrm{Y} & \mathrm{Y} & \mathrm{Y} & \mathrm{Y} & \mathrm{N} & \mathrm{N} & \mathrm{N} & \mathrm{Y} & \mathrm{N} & \mathrm{N} & \text { n/a } & \text { n/a } & \mathrm{N} & \mathrm{N} & \mathrm{n} / \mathrm{a} & \mathrm{N} & 38 \%\end{array}$

$\begin{array}{llllllllllllllllll}\text { Dunst et al., (2013). } & \text { Y } & \text { Y } & \text { Y } & \text { Y } & \text { N } & \text { N } & \text { N } & \text { Y } & \text { N } & \text { N } & \text { Y } & \text { Y } & \text { Y } & \text { N } & \text { N } & \text { Y } & 63 \%\end{array}$

$\begin{array}{lllllllllllllllllll}\text { Erdem, (2017). } & \mathrm{Y} & \mathrm{Y} & \mathrm{Y} & \mathrm{Y} & \mathrm{N} & \mathrm{N} & \mathrm{N} & \mathrm{N} & \mathrm{N} & \mathrm{N} & \mathrm{n} / \mathrm{a} & \mathrm{n} / \mathrm{a} & \mathrm{N} & \mathrm{N} & \mathrm{n} / \mathrm{a} & \mathrm{N} & 31 \%\end{array}$

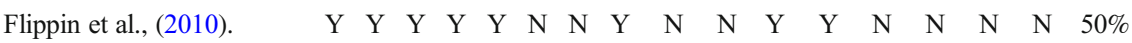

$\begin{array}{llllllllllllllllll}\text { Ganz et al., (2012a). PECS } & Y & Y & Y & Y & Y & Y & N & Y & N & N & Y & Y & N & N & n / a & N & 60 \%\end{array}$

$\begin{array}{lllllllllllllllllll}\text { Ganz et al., (2012b). Aided } & Y & Y & Y & Y & Y & Y & N & Y & N & N & Y & Y & N & N & N & N & 56 \%\end{array}$ AAC

$\begin{array}{lllllllllllllllllll}\text { Ganz et al., (2014a). Partic- } & \text { Y } & \text { Y } & \text { Y } & \text { Y } & \text { Y } & \text { Y } & \text { N } & \text { Y } & \text { Y } & \text { N } & \text { Y } & \text { Y } & \text { N } & \text { Y } & \text { N } & \text { N } & 73 \%\end{array}$ ipant characteristics.

Ganz et al., (2017).

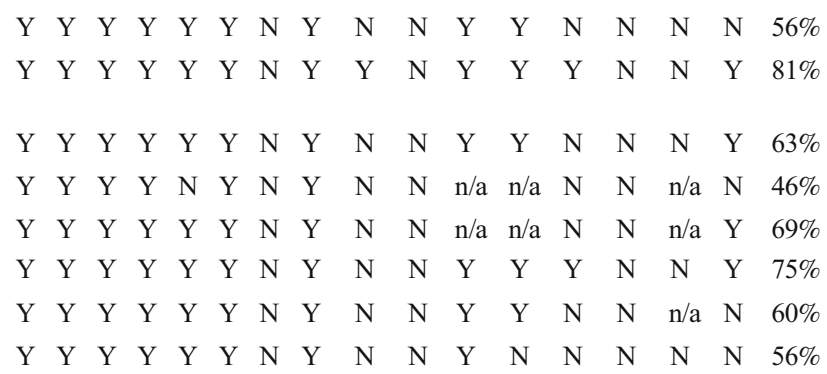
$\begin{array}{lllllllllllllllll}\mathrm{Y} & \mathrm{Y} & \mathrm{Y} & \mathrm{Y} & \mathrm{Y} & \mathrm{Y} & \mathrm{N} & \mathrm{Y} & \mathrm{Y} & \mathrm{N} & \mathrm{Y} & \mathrm{Y} & \mathrm{Y} & \mathrm{N} & \mathrm{N} & \mathrm{Y} & 81 \%\end{array}$

$\begin{array}{lllllllllllllllll}\mathrm{Y} & \mathrm{Y} & \mathrm{Y} & \mathrm{Y} & \mathrm{Y} & \mathrm{Y} & \mathrm{N} & \mathrm{Y} & \mathrm{N} & \mathrm{N} & \mathrm{Y} & \mathrm{Y} & \mathrm{N} & \mathrm{N} & \mathrm{N} & \mathrm{Y} & 63 \%\end{array}$

$\begin{array}{lllllllllllllllll}\mathrm{Y} & \mathrm{Y} & \mathrm{Y} & \mathrm{Y} & \mathrm{N} & \mathrm{Y} & \mathrm{N} & \mathrm{Y} & \mathrm{N} & \mathrm{N} & \mathrm{n} / \mathrm{a} & \mathrm{n} / \mathrm{a} & \mathrm{N} & \mathrm{N} & \mathrm{n} / \mathrm{a} & \mathrm{N} & 46 \%\end{array}$

$\begin{array}{lllllllllllllllll}Y & Y & Y & Y & Y & Y & N & Y & N & N & n / a & n / a & N & N & n / a & Y & 69 \%\end{array}$

$\begin{array}{lllllllllllllllll}\mathrm{Y} & \mathrm{Y} & \mathrm{Y} & \mathrm{Y} & \mathrm{Y} & \mathrm{Y} & \mathrm{N} & \mathrm{Y} & \mathrm{N} & \mathrm{N} & \mathrm{Y} & \mathrm{Y} & \mathrm{Y} & \mathrm{N} & \mathrm{N} & \mathrm{Y} & 75 \%\end{array}$

$\begin{array}{lllllllllllllllll}\mathrm{Y} & \mathrm{Y} & \mathrm{Y} & \mathrm{Y} & \mathrm{Y} & \mathrm{Y} & \mathrm{N} & \mathrm{Y} & \mathrm{N} & \mathrm{N} & \mathrm{Y} & \mathrm{Y} & \mathrm{N} & \mathrm{N} & \mathrm{n} / \mathrm{a} & \mathrm{N} & 60 \%\end{array}$

$\begin{array}{lllllllllllllllll}\mathrm{Y} & \mathrm{Y} & \mathrm{Y} & \mathrm{Y} & \mathrm{Y} & \mathrm{Y} & \mathrm{N} & \mathrm{Y} & \mathrm{N} & \mathrm{N} & \mathrm{Y} & \mathrm{N} & \mathrm{N} & \mathrm{N} & \mathrm{N} & \mathrm{N} & 56 \%\end{array}$

Ganz et al., (2014b). Ssetting and types.

Gevarter et al., (2013).

Gilson et al., (2017).

Hart \& Banda, (2010).

Heath et al. (2015).

Holyfield et al., (2017). 
Table 4 (continued)

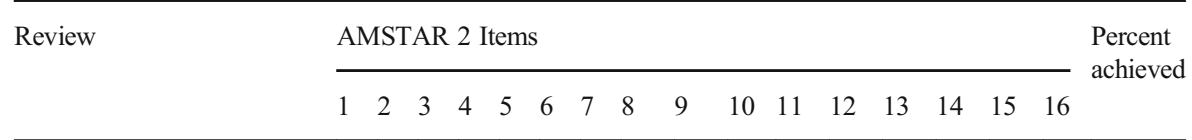

Hong et al., (2017).

Iacono et al., (2016).

$\begin{array}{lllllllllllllllll}\mathrm{Y} & \mathrm{Y} & \mathrm{Y} & \mathrm{Y} & \mathrm{Y} & \mathrm{Y} & \mathrm{N} & \mathrm{Y} & \mathrm{N} & \mathrm{N} & \mathrm{Y} & \mathrm{Y} & \mathrm{N} & \mathrm{N} & \mathrm{N} & \mathrm{Y} & 69 \%\end{array}$

Kent-Walsh et al., (2015).

$\begin{array}{lllllllllllllllll}\mathrm{Y} & \mathrm{Y} & \mathrm{Y} & \mathrm{Y} & \mathrm{Y} & \mathrm{N} & \mathrm{N} & \mathrm{Y} & \mathrm{N} & \mathrm{N} & \mathrm{n} / \mathrm{a} & \mathrm{n} / \mathrm{a} & \mathrm{N} & \mathrm{N} & \mathrm{n} / \mathrm{a} & \mathrm{Y} & 62 \%\end{array}$

Kim \& Kimm, (2017). $\begin{array}{lllllllllllllllll}\mathrm{Y} & \mathrm{Y} & \mathrm{Y} & \mathrm{Y} & \mathrm{N} & \mathrm{Y} & \mathrm{N} & \mathrm{Y} & \mathrm{N} & \mathrm{N} & \mathrm{Y} & \mathrm{Y} & \mathrm{Y} & \mathrm{Y} & \mathrm{N} & \mathrm{Y} & 69 \%\end{array}$

Lancioni et al. (2007).

$\begin{array}{lllllllllllllllll}\mathrm{N} & \mathrm{Y} & \mathrm{Y} & \mathrm{Y} & \mathrm{N} & \mathrm{Y} & \mathrm{N} & \mathrm{Y} & \mathrm{N} & \mathrm{N} & \mathrm{Y} & \mathrm{Y} & \mathrm{Y} & \mathrm{Y} & \mathrm{N} & \mathrm{N} & 56 \%\end{array}$

Lancioni et al., (2001).

$\begin{array}{lllllllllllllllll}\mathrm{Y} & \mathrm{Y} & \mathrm{Y} & \mathrm{Y} & \mathrm{N} & \mathrm{N} & \mathrm{N} & \mathrm{Y} & \mathrm{N} & \mathrm{N} & \mathrm{n} / \mathrm{a} & \mathrm{n} / \mathrm{a} & \mathrm{N} & \mathrm{N} & \mathrm{n} / \mathrm{a} & \mathrm{N} & 38 \%\end{array}$

Logan et al., (2017).

$\begin{array}{llllllllllllllll}\mathrm{N} & \mathrm{N} & \mathrm{N} & \mathrm{N} & \mathrm{N} & \mathrm{N} & \mathrm{N} & \mathrm{Y} & \mathrm{N} & \mathrm{n} / \mathrm{a} & \mathrm{n} / \mathrm{a} & \mathrm{n} / \mathrm{a} & \mathrm{n} / \mathrm{a} & \mathrm{n} / \mathrm{a} & \mathrm{N} & 10 \%\end{array}$

Lorah et al., (2015).

$\begin{array}{llllllllllllllllll}\mathrm{Y} & \mathrm{Y} & \mathrm{Y} & \mathrm{Y} & \mathrm{Y} & \mathrm{Y} & \mathrm{N} & \mathrm{Y} & \mathrm{N} & \mathrm{N} & \mathrm{N} & \mathrm{n} / \mathrm{a} & \mathrm{n} / \mathrm{a} & \mathrm{Y} & \mathrm{N} & \mathrm{Y} & 71 \%\end{array}$

Lynch et al., (2018).

$\begin{array}{lllllllllllllllll}\mathrm{Y} & \mathrm{Y} & \mathrm{Y} & \mathrm{Y} & \mathrm{Y} & \mathrm{Y} & \mathrm{N} & \mathrm{Y} & \mathrm{Y} & \mathrm{N} & \mathrm{n} / \mathrm{a} & \mathrm{n} / \mathrm{a} & \mathrm{N} & \mathrm{Y} & \mathrm{n} / \mathrm{a} & \mathrm{N} & 69 \%\end{array}$

$\begin{array}{llllllllllllllllll}\text { Machalicek et al., (2010). } & \text { Y } & Y & Y & Y & Y & Y & N & Y & N & N & n / a & n / a & Y & Y & n / a & N & 77 \%\end{array}$

Mancil (2006).

$\begin{array}{lllllllllllllllll}Y & Y & Y & Y & Y & Y & N & Y & N & N & n / a & n / a & N & Y & n / a & N & 62 \%\end{array}$

Millar et al., (2006).

$\begin{array}{lllllllllllllllll}\mathrm{Y} & \mathrm{Y} & \mathrm{Y} & \mathrm{Y} & \mathrm{N} & \mathrm{N} & \mathrm{N} & \mathrm{Y} & \mathrm{N} & \mathrm{N} & \mathrm{n} / \mathrm{a} & \mathrm{n} / \mathrm{a} & \mathrm{N} & \mathrm{N} & \mathrm{n} / \mathrm{a} & \mathrm{N} & 38 \%\end{array}$

Morin et al., (2018).

Muharib et al. (2018).

$\begin{array}{lllllllllllllllll}N & Y & Y & Y & Y & Y & N & Y & N & N & n / a & n / a & N & N & n / a & N & 46 \%\end{array}$

Murray et al., (2014).

$\begin{array}{lllllllllllllllll}\mathrm{Y} & \mathrm{Y} & \mathrm{Y} & \mathrm{Y} & \mathrm{N} & \mathrm{Y} & \mathrm{N} & \mathrm{Y} & \mathrm{Y} & \mathrm{N} & \mathrm{n} / \mathrm{a} & \mathrm{n} / \mathrm{a} & \mathrm{Y} & \mathrm{N} & \mathrm{n} / \mathrm{a} & \mathrm{Y} & 77 \%\end{array}$

Nam et al., (2018).

$\begin{array}{lllllllllllllllll}Y & Y & Y & Y & Y & Y & N & Y & N & N & Y & Y & N & N & n / a & Y & 67 \%\end{array}$

O’Neill et al., (2018).

$\begin{array}{lllllllllllllllll}Y & Y & Y & Y & Y & Y & N & Y & Y & N & n / a & n / a & Y & N & n / a & N & 77 \%\end{array}$

Odom et al., (2015).

Ok, (2018).

$\begin{array}{lllllllllllllllll}\mathrm{Y} & \mathrm{Y} & \mathrm{Y} & \mathrm{Y} & \mathrm{Y} & \mathrm{Y} & \mathrm{N} & \mathrm{Y} & \mathrm{N} & \mathrm{N} & \mathrm{Y} & \mathrm{Y} & \mathrm{N} & \mathrm{Y} & \mathrm{N} & \mathrm{Y} & 67 \%\end{array}$

$\begin{array}{lllllllllllllllll}\mathrm{Y} & \mathrm{Y} & \mathrm{Y} & \mathrm{Y} & \mathrm{N} & \mathrm{N} & \mathrm{N} & \mathrm{Y} & \mathrm{N} & \mathrm{N} & \mathrm{n} / \mathrm{a} & \mathrm{n} / \mathrm{a} & \mathrm{N} & \mathrm{N} & \mathrm{n} / \mathrm{a} & \mathrm{N} & 38 \%\end{array}$

$\begin{array}{lllllllllllllllll}\mathrm{N} & \mathrm{Y} & \mathrm{Y} & \mathrm{Y} & \mathrm{N} & \mathrm{N} & \mathrm{N} & \mathrm{N} & \mathrm{N} & \mathrm{N} & \text { na } & \mathrm{n} / \mathrm{a} & \mathrm{N} & \mathrm{N} & \mathrm{n} / \mathrm{a} & \mathrm{N} & 31 \%\end{array}$

Ostryn et al., (2008).

$\begin{array}{lllllllllllllllll}\mathrm{Y} & \mathrm{Y} & \mathrm{Y} & \mathrm{Y} & \mathrm{N} & \mathrm{N} & \mathrm{N} & \mathrm{Y} & \mathrm{N} & \mathrm{N} & \mathrm{n} / \mathrm{a} & \mathrm{n} / \mathrm{a} & \mathrm{N} & \mathrm{N} & \mathrm{n} / \mathrm{a} & \mathrm{N} & 38 \%\end{array}$

Østvik et al., (2017).

Pinto et al., (2009).

$\begin{array}{lllllllllllllllll}\mathrm{N} & \mathrm{N} & \mathrm{Y} & \mathrm{Y} & \mathrm{N} & \mathrm{N} & \mathrm{N} & \mathrm{Y} & \mathrm{N} & \mathrm{N} & \mathrm{n} / \mathrm{a} & \mathrm{n} / \mathrm{a} & \mathrm{N} & \mathrm{N} & \mathrm{N} & \mathrm{N} & 21 \%\end{array}$

$\begin{array}{lllllllllllllllll}\mathrm{Y} & \mathrm{Y} & \mathrm{Y} & \mathrm{Y} & \mathrm{N} & \mathrm{Y} & \mathrm{N} & \mathrm{Y} & \mathrm{N} & \mathrm{N} & \mathrm{n} / \mathrm{a} & \mathrm{n} / \mathrm{a} & \mathrm{N} & \mathrm{N} & \mathrm{n} / \mathrm{a} & \mathrm{Y} & 54 \%\end{array}$

Preston \& Carter, (2009).

Ramdoss et al., (2011).

$\begin{array}{lllllllllllllllll}\mathrm{N} & \mathrm{N} & \mathrm{N} & \mathrm{N} & \mathrm{N} & \mathrm{N} & \mathrm{N} & \mathrm{Y} & \mathrm{N} & \mathrm{N} & \mathrm{n} / \mathrm{a} & \mathrm{n} / \mathrm{a} & \mathrm{N} & \mathrm{N} & \mathrm{n} / \mathrm{a} & \mathrm{N} & 8 \%\end{array}$

Rispoli et al., (2010).

$\begin{array}{lllllllllllllllll}\mathrm{Y} & \mathrm{Y} & \mathrm{Y} & \mathrm{Y} & \mathrm{N} & \mathrm{Y} & \mathrm{N} & \mathrm{Y} & \mathrm{N} & \mathrm{N} & \mathrm{Y} & \mathrm{Y} & \mathrm{N} & \mathrm{Y} & \mathrm{n} / \mathrm{a} & \mathrm{N} & 60 \%\end{array}$

Roche et al., (2014).

$\begin{array}{lllllllllllllllll}Y & Y & Y & Y & N & Y & N & Y & N & N & n / a & n / a & N & N & n / a & N & 46 \%\end{array}$

Roche et al., (2015).

$\begin{array}{lllllllllllllllll}Y & Y & Y & Y & Y & Y & N & Y & N & N & n / a & n / a & n / a & n / a & n / a & Y & 80 \%\end{array}$

$\begin{array}{lllllllllllllllll}Y & Y & Y & Y & Y & Y & N & Y & N & N & n / a & n / a & Y & Y & Y & Y & 86 \%\end{array}$

Romski et al., (2015).

$\begin{array}{lllllllllllllllll}Y & Y & Y & Y & Y & Y & N & Y & N & N & n / a & n / a & Y & Y & n / a & Y & 85 \%\end{array}$

$\begin{array}{llllllllllllllllll}\text { Schlosser \& Wendt, (2008). } & Y & Y & Y & Y & Y & N & N & Y & N & N & n / a & n / a & N & N & n / a & Y & 54 \%\end{array}$

$\begin{array}{lllllllllllllllllll}\text { Schlosser \& } & \text { Y } & \text { Y } & \text { Y } & \text { Y } & \text { Y } & \text { Y } & \text { Y } & \text { Y } & \text { N } & \text { N } & \text { Y } & \text { Y } & \text { N } & \text { Y } & \text { N } & \text { N } & 69 \%\end{array}$

Blischak, (2001).

$\begin{array}{lllllllllllllllllll}\text { Schlosser et al., (2014). } & \text { Y } & Y & Y & Y & N & N & N & Y & N & N & n / a & n / a & N & N & n / a & N & 38 \%\end{array}$

$\begin{array}{lllllllllllllllllll}\text { Sennott et al., (2016). } & \text { Y } & \text { Y } & \text { Y } & \text { Y } & N & N & Y & Y & N & N & n / a & n / a & Y & N & \text { n/a } & Y & 69 \%\end{array}$

$\begin{array}{lllllllllllllllllll}\text { Shire \& Jones, (2015). } & \text { Y } & Y & Y & Y & N & Y & N & Y & Y & N & n / a & n / a & Y & Y & n / a & Y & 85 \%\end{array}$

$\begin{array}{llllllllllllllllll}\text { Sievers et al., (2018). } \quad & N & N & Y & Y & N & N & N & Y & Y & N & n / a & n / a & Y & N & n / a & Y & 46 \%\end{array}$

$\begin{array}{llllllllllllllllllll}\text { Smith \& Iadarola, (2015). } & \text { Y } & \text { Y } & \text { Y } & \text { Y } & \text { Y } & \text { Y } & \text { N } & \text { Y } & \text { Y } & \text { N } & \text { Y } & \text { Y } & \text { Y } & \text { Y } & \text { N } & \text { Y } & 88 \%\end{array}$

$\begin{array}{llllllllllllllllllllllllll}\text { Snell et al., (2006). } & N & Y & Y & Y & N & N & N & Y & N & N & n / a & n / a & n / a & N & n / a & N & 33 \%\end{array}$

$\begin{array}{llllllllllllllllll}\text { Stauter et al., (2017). } & \text { Y } & Y & Y & Y & Y & Y & N & Y & N & N & n / a & n / a & N & N & N & N & 50 \%\end{array}$

$\begin{array}{lllllllllllllllllll}\text { Stephenson \& } & \text { Y } & \text { Y } & \text { Y } & \text { Y } & \text { N } & \text { Y } & N & Y & Y & N & n / a & n / a & Y & N & N & N & 57 \%\end{array}$

Limbrick, (2015).

Still et al., (2014).

$\begin{array}{lllllllllllllllllll}\mathrm{Y} & \mathrm{Y} & \mathrm{Y} & \mathrm{Y} & \mathrm{Y} & \mathrm{Y} & \mathrm{N} & \mathrm{Y} & \mathrm{Y} & \mathrm{N} & \mathrm{Y} & \mathrm{Y} & \mathrm{N} & \mathrm{Y} & \mathrm{N} & \mathrm{N} & 69 \%\end{array}$ 
Table 4 (continued)

\begin{tabular}{|c|c|c|c|c|c|c|c|c|c|c|c|c|c|c|c|c|c|}
\hline \multirow[t]{2}{*}{ Review } & \multicolumn{16}{|c|}{ AMSTAR 2 Items } & \multirow{2}{*}{$\begin{array}{l}\text { Percent } \\
\text { achieved }\end{array}$} \\
\hline & 1 & 2 & 3 & 4 & 5 & 6 & 7 & 8 & 9 & 10 & 11 & 12 & 13 & 14 & 15 & 16 & \\
\hline $\begin{array}{l}\text { Sulzer-Azaroff } \\
\text { et al., (2009). }\end{array}$ & $\mathrm{Y}$ & $\mathrm{N}$ & $\mathrm{Y}$ & $\mathrm{Y}$ & $\mathrm{N}$ & $\mathrm{N}$ & $\mathrm{N}$ & $\mathrm{Y}$ & $\mathrm{N}$ & $\mathrm{N}$ & $\mathrm{n} / \mathrm{a}$ & $\mathrm{n} / \mathrm{a}$ & $\mathrm{N}$ & $\mathrm{N}$ & $\mathrm{n} / \mathrm{a}$ & $\mathrm{Y}$ & $38 \%$ \\
\hline Therrien et al., (2016). & $\mathrm{Y}$ & $\mathrm{Y}$ & $\mathrm{Y}$ & $\mathrm{Y}$ & $\mathrm{Y}$ & $\mathrm{Y}$ & $\mathrm{N}$ & $\mathrm{Y}$ & $\mathrm{N}$ & $\mathrm{N}$ & $\mathrm{n} / \mathrm{a}$ & $\mathrm{n} / \mathrm{a}$ & $\mathrm{N}$ & $\mathrm{Y}$ & $\mathrm{N}$ & $\mathrm{N}$ & $57 \%$ \\
\hline Tien, (2008). & $\mathrm{Y}$ & $\mathrm{N}$ & $\mathrm{Y}$ & $\mathrm{Y}$ & $\mathrm{N}$ & $\mathrm{Y}$ & $\mathrm{N}$ & $\mathrm{Y}$ & $\mathrm{Y}$ & $\mathrm{N}$ & $\mathrm{Y}$ & $\mathrm{Y}$ & $\mathrm{Y}$ & $\mathrm{Y}$ & $\mathrm{N}$ & $\mathrm{Y}$ & $75 \%$ \\
\hline Tincani \& Devis, (2011) & $\mathrm{Y}$ & $\mathrm{Y}$ & $\mathrm{Y}$ & $\mathrm{Y}$ & $\mathrm{N}$ & $\mathrm{N}$ & $\mathrm{N}$ & $\mathrm{Y}$ & $\mathrm{N}$ & $\mathrm{N}$ & $\mathrm{n} / \mathrm{a}$ & $\mathrm{n} / \mathrm{a}$ & $\mathrm{n} / \mathrm{a}$ & $\mathrm{n} / \mathrm{a}$ & $\mathrm{n} / \mathrm{a}$ & $\mathrm{N}$ & $56 \%$ \\
\hline $\begin{array}{l}\text { Van Der Meer \& } \\
\text { Rispoli. (2010). }\end{array}$ & $\mathrm{Y}$ & $\mathrm{Y}$ & $\mathrm{Y}$ & $\mathrm{Y}$ & Y & $\mathrm{Y}$ & $\mathrm{N}$ & $\mathrm{Y}$ & $\mathrm{N}$ & $\mathrm{N}$ & $\mathrm{Y}$ & $\mathrm{Y}$ & $\mathrm{N}$ & $\mathrm{Y}$ & $\mathrm{N}$ & $\mathrm{Y}$ & $75 \%$ \\
\hline Van der Meer et al., (2011). & $\mathrm{Y}$ & $\mathrm{Y}$ & $\mathrm{Y}$ & $\mathrm{Y}$ & $\mathrm{Y}$ & $\mathrm{N}$ & $\mathrm{N}$ & $\mathrm{Y}$ & $\mathrm{N}$ & $\mathrm{N}$ & $\mathrm{n} / \mathrm{a}$ & $\mathrm{n} / \mathrm{a}$ & $\mathrm{N}$ & $\mathrm{N}$ & $\mathrm{n} / \mathrm{a}$ & $\mathrm{Y}$ & $54 \%$ \\
\hline Walker \& Snell, (2013). & $\mathrm{Y}$ & $\mathrm{Y}$ & $\mathrm{Y}$ & $\mathrm{Y}$ & $\mathrm{Y}$ & $\mathrm{Y}$ & $\mathrm{N}$ & $\mathrm{Y}$ & $\mathrm{Y}$ & $\mathrm{N}$ & $\mathrm{n} / \mathrm{a}$ & $\mathrm{n} / \mathrm{a}$ & $\mathrm{Y}$ & $\mathrm{N}$ & $\mathrm{N}$ & $\mathrm{Y}$ & $71 \%$ \\
\hline Walker, V. L. et al. (2018). & $\mathrm{Y}$ & $\mathrm{Y}$ & $\mathrm{Y}$ & $\mathrm{Y}$ & $\mathrm{Y}$ & $\mathrm{Y}$ & $\mathrm{Y}$ & $\mathrm{Y}$ & $\mathrm{Y}$ & $\mathrm{N}$ & $\mathrm{Y}$ & $\mathrm{Y}$ & $\mathrm{Y}$ & $\mathrm{Y}$ & $\mathrm{Y}$ & $\mathrm{Y}$ & $94 \%$ \\
\hline
\end{tabular}

Raharinirina, 2006), and training natural communication partners were most frequently mentioned as areas of future research by review authors. Researching the impact of different user interfaces was recommended in two reviews (Lorah et al., 2015; van der Meer et al., 2011), and investigating symbol arrays on communication outcomes was recommended in three reviews (Lynch et al., 2018; Morin et al., 2018; Roche et al., 2014). Rapid developments and changes in technology, user interfaces, symbol languages, and specifically advances in multi-use mobile technology were mentioned as reasons to research AAC devices other than dedicated SGDs. These review authors also recommended investigating user experiences when interacting with technology and exploring different designs and interfaces with various users to better meet their needs (Lorah et al., 2015).

Another area of further research recommended by review authors was investigating the effects of different types of speech output (Drager et al., 2010; Schlosser \& Blischak, 2001). Comparisons of intelligibility of digitized and synthesized speech led to further questions about whether environmental noise impacts intelligibility of $\mathrm{AAC}$ voices, and recommendations that researchers examine the intelligibility and comprehension of AAC device voices by the user's same age peers (Drager et al., 2010).

Researching comparative effectiveness of types of AAC, (e.g., aided and unaided AAC), was an area of future research recommended by authors of seven reviews (Branson \& Demchak, 2009; Brunner \& Seung, 2009; Cumming \& Draper Rodriguez, 2017; Logan et al., 2017; Lorah et al., 2015; Preston \& Carter, 2009; Therrien et al., 2016). While some reviews addressed comparing effectiveness of different types of AAC (e.g., Ganz et al., 2012b; Ganz et al., 2017; Holyfield et al., 2017; van der Meer et al., 2011), further research is warranted so that clinicians and educators have an evidence based rationale for selecting specific types of AAC for an individual's needs and preferences. Recommendations included that researchers perform comparison studies of different AAC modalities (Brunner \& Seung, 2009), mobile technology to more traditional AAC (Cumming \& Draper Rodriguez, 2017), and different AAC programs and apps (Lorah et al., 2015). 
Multiple reviews recommended further investigation into interventions aimed at training natural communication partners such as parents and teachers to communicate using AAC with individuals who have complex communication needs (Kent-Walsh et al., 2015; Logan et al., 2017; Mancil, 2006; Morin et al., 2018; Shire \& Jones, 2015; Snell et al., 2006; Stauter et al., 2017; Tincani \& Devis, 2011; Walker \& Snell, 2013). Training communication partners other than the researcher on interventions and using them as natural change agents could lead to more socially valid intervention outcomes, more successful generalization, higher maintenance of communicative behaviors, and integrate AAC interventions into natural contexts.

Research on effective dosage, or amount of treatment, of AAC interventions was explicitly mentioned by one review (Sennott et al., 2016) with specific recommendations to examine variables relating to service delivery by speechlanguage pathologists in school settings. Sennott et al. (2016) recommended that researchers examine the impact of language interventions across the lifespan and how contextual and personal changes affect AAC intervention needs, dosage, and communication skills such as vocabulary.

Further research on the effects of AAC interventions on academic skills was recommended by 4 reviews (Ganz et al., 2014a; Ganz et al., 2017; Hong et al., 2017; Still et al., 2014). Other reviews recommended further research on the impact of technology aided instruction on literacy outcomes (Barker et al., 2012; Boyle et al., 2017; Machalicek et al., 2010; Stauter et al., 2017).

Investigating the impact of AAC intervention on independence and social interactions such as friendships was recommended in 6 reviews (Bryant et al., 2010; Chung et al., 2012; Cumming \& Draper Rodríguez, 2017; Holyfield et al., 2017; Østvik et al., 2017; Therrien et al., 2016). While social interactions were identified as areas for future research, the reviews included specific calls to action to explore the impact of AAC interventions on peer interactions and supportive relationships for students with disabilities in middle and high school settings (Chung et al., 2012). Areas of future research specific to social relationships were developing indicators of social relationships and operationalizing definitions of friendship (Østvik et al., 2017; Therrien et al., 2016).

Integrating and increasing collaboration among parents, researchers, teachers, and service providers throughout the research process was recommended by 5 reviews (Alper \& Raharinirina, 2006; Alquraini \& Gut, 2012; Andzik et al., 2016; Logan et al., 2017; Pinto et al., 2009). These authors called for increasing input from stakeholders throughout all parts of the research process, which is a recommendation of participatory research practices (Bailey et al., 2015). Increasing collaboration and participation by stakeholders could also increase social validity and generalizability of empirical interventions to more natural settings (Alper \& Raharinirina, 2006). Desideri and colleagues (2013) recommended transitioning research away from the decontextualized experiences of researchers to incorporate effective models for low incidence disabilities, specifically children with multiple disabilities, and increasing collaboration with individuals with disabilities, hearing their experiences, and designing research with participants to best meet their areas of need. They also recommend evaluating the cost effectiveness of assistive technology interventions to address the financial burden on the family. 


\section{Participant Demographics}

Reviews reporting on included studies' reporting of race and ethnicity data for participants were very few $(n=4)$. Reporting this information is crucial not only to answer the question of for whom does this intervention work, but also to assist researchers working to identify mediators and moderators of intervention effectiveness. This paucity of race/ethnicity reporting possibly reflects the need for greater participant diversity in special education research (Sinclair et al., 2018). Non-binary gender identifications were not reported in any of the reviews, further contributing to the oppression and erasure of the identities of individuals with multiple sites for marginalization (Duke, 2011), or intersectionality (Crenshaw et al., 1996). Research participant demographics do not proportionately represent national demographics or reflect school classroom populations, limiting generalizability and recommendations for diverse populations of students (Spear et al., 2013). Examining whether family poverty, urban or rural environments, race and ethnicity, and specific factors related to disability categories impact the effectiveness of interventions and best practices will be crucial as educational policy and practices shift (Singer et al., 2017).

Researchers can create richer, more relevant, and more robust AAC interventions to increase the field's knowledge of different experiences with living with AAC and increase points of entry and topics for intervention to increase communicative competencies and quality of life for individuals with complex communication needs (Chan \& Zoellick, 2011). Research on the experiences and outcomes of AAC interventions with linguistically diverse individuals with disabilities who use aided AAC is a growing area within the literature (Kulkarni \& Parmar, 2017). Determining language preference for instruction and language output of aided AAC (Aguilar et al., 2016; Kunze et al., 2019) and incorporating cultural views of AAC users, their families, and stakeholders are areas requiring exploration (Kulkarni \& Parmar, 2017) in the field of AAC interventions.

The predominance of single-case research designs in the field of special education affords AAC researchers the ability to report more specific and individualized information about participants to aid in direct and systematic replication of effective interventions and increase the known pool of students for whom specific interventions work (Horner et al., 2005). The cornerstone of the Individuals with Disabilities Educational Improvement Act (2004) and the individualized education program emphasize the "individual" as the driving force behind development of interventions for a student with disabilities. Understanding research as a practice in partnership with participants and understanding that researchers bring their own theoretical frameworks, implicit biases, and personal understandings of constructs including dis/ability, race, gender, sexual orientation, and appropriate behavioral outcomes (Arzubiaga et al., 2008), will help move research on AAC interventions forward.

\section{Social Validity}

One crucial area that the AMSTAR-2 does not address is the social validity of either the studies included in the reviews and the reviews themselves. One way to improve social and ecological validity is by increasing the participation of research subjects, their families, educators, and other community stakeholders in the development of research 
questions, selection of conceptual frameworks, types of interventions used, which outcomes are measured, and what data is reported and through which channels. While individual studies in the included reviews may have assessed and reported social validity, many included reviews did not report on or discuss social validity measures or findings. Without data on the acceptability of treatments and interventions, researchers and practitioners may be reluctant to select interventions that are not be acceptable to stakeholders, potentially leading to lack of contextual fit, lower rates of intervention treatment fidelity, and lower rates of treatment adherence (Spear et al., 2013).

For children who use AAC to communicate, assessing consumer satisfaction should involve the AAC user to the greatest extent possible. A familiar adult and same age peer could ask the AAC user for their input, providing the researcher with a richer analysis of the user's experience told to different and ecologically valid communication partners. Directly asking the user about their experiences before, during, and after intervention, especially involving the user from the beginning stages of research development would increase targeting user-important skills and increase intervention relevance to the user, possibly increasing buy-in and motivation to adhere to and complete the intervention (Leko, 2014).

\section{Generalization and Maintenance}

Generalization and maintenance were identified by many review authors as areas of need, both for study authors to program from inception and for increased reporting out in manuscripts. Other researchers have analyzed and offered suggestions for increasing programming for generalization and collecting data on maintenance of skills at longer intervals after intervention ends (Schlosser \& Lee, 2000) yet underutilization or underreporting of both persist. In AAC research, bringing functional communication skills under stimulus control may require additional programming during intervention or follow up interventions after the user has learned the communication skill to then teach discrimination of under which conditions to exhibit that target behavior. Specifically, researchers could program for intervention in the natural environment of the AAC user (Schlosser \& Lee, 2000). Conducting an intervention session in the school cafeteria, in the classroom with the general education teacher as the interventionist, or on a field trip could decrease stimulus control of a specific learning setting and increase behavioral momentum of the target skill (Mace \& Nevin, 2017). If changing intervention settings is not feasible, incorporating more communication partners such as the AAC user's schoolmates and teachers could increase generalization and increase the social validity of using an AAC system across multiple communication partners.

Training the most frequent communication partners of individuals who use AAC would enhance both generalization and maintenance of the newly acquired skills. Generalization in the absence of reinforcement places the target behavior on extinction, resulting in sharp decreases in responding and potential increases in problem behavior (Mace \& Nevin, 2017). Training communication partners on strategies such as sitting close enough to the AAC user to see the communication system and signal their availability as an audience, assessing and using the communication partner's skills as 
a jumping off point for coaching and intervention on responsiveness, and training the communication partner to recognize and respond to the user's communicative initiations could increase the frequency of the AAC user's communication behaviors and opportunities to contact natural reinforcement (Calculator, 1988).

\section{Communication Breakdown}

Another aspect of programming for generalization and accounting for maintenance of acquired skills over time would involve teaching the AAC user what to do in the event of communication breakdown (Calculator, 1988). Speech-generating devices can be unreliable (Baxter et al., 2012) and can run out of battery or be unavailable due to being sent out for repair or updates (Cooper et al., 2009). AAC interventions incorporating backup strategies for the user to employ if the high-tech communication device breaks or is unavailable, or if the communication partner does not understand the communicative act by the user (Calculator, 1988) would increase communicative opportunities for the person who uses AAC. Teaching the AAC user to use picture symbols, gestures, or other means of aiding the communication partner in understanding the message (Halle et al., 2004) would increase generalization of the specific target behaviors across novel contexts and communication partners. This in turn could increase maintenance of the target skills over time since the user has multiple means of conveying their message to others, thus reinforcing the behavior with natural consequences outside of the clinical setting and with novel communication partners. Future research on increasing response variability and use of alternate methods of communication are warranted.

\section{Maintenance}

When planning maintenance probes in coordination with school calendars, planning for maintenance data collection further out than 1 to 2 weeks after an intervention ends would help researchers and clinicians make decisions about effective interventions for lasting behavior change. Just as teachers use maintenance data over fall and winter breaks to assess whether students require extended school year services to maintain skills gained during the school year, researchers could probe maintenance after students return from holiday breaks.

With increased use, ease of access, and prevalence of technological communication systems, researchers can check in with AAC users and stakeholders without much time and cost investment. Researchers can check in via email, video teleconferencing software, text message, or direct message through social media with links to online surveys or conduct a telehealth-type consultation for data collection. Surveys or interviews could also be used to inform future intervention development as well as assist researchers with decision rules to re-teach the target skill or modify the original intervention for re-teaching.

The use of videoconferencing software such as Zoom for Healthcare is an emerging area within the evidence base made all the more important by recent school and clinic closures due to the global pandemic. Telehealth intervention delivery can address chronic shortages of trained and skilled professionals, provide services to families living in remote areas or who cannot travel, and increase access to evidence based practices by both families and practitioners. Clinicians and researchers can use 
telehealth technology to provide direct services to individuals with complex communication needs, train parents/caregivers, and train practitioners to deliver evidencebased practices. With the increasing reliance on telehealth technology due to the COVID-19 global pandemic, rigorously designed research studies exploring distance technology for direct service provision and communication partner intervention delivery is both warranted and sorely needed. Research into reducing disparities in access and technology exacerbated by telehealth is also needed: reaching rural, remote, and underresourced individuals with CCN remains an area of need for further research and professional development for practitioners.

\section{Vocabulary}

AAC vocabulary is often selected by adults, particularly parents and professionals (Trembath et al., 2007), who carefully curate frequently used or socially appropriate vocabulary for the AAC user, potentially without considering what the user's peers are actually saying to each other. Observing the AAC user's same age peers and collecting language samples in a variety of contexts and with a variety of conversation partners (teachers, parents, friends) would yield more ecologically valid communication targets and vocabulary (Schwartz \& Baer, 1991). Incorporating socially valid but not necessarily school appropriate vocabulary (Ashby et al., 2016) such as potty-themed jokes for a kindergartner, masturbation terms for a high schooler, or alcoholic beverages for an adult is often ignored by parents and professionals who may find discussion of these topics difficult and uncomfortable. These are topics the user may want to access to increase social interactions and participation with peers (Bryen, 2009; Smith, 2015).

\section{Limitations and Future Directions}

This mega-review has several limitations, primarily that reviews of reviews have the inherent weakness of relying on information provided about individual studies within the review. Authors of prior reviews may have poorly defined their inclusion and exclusion criteria, failed to correctly extract data from the articles, or may have inadequately analyzed and reported on the findings across the reviewed studies. Reviews were not excluded from analysis based on quality and summarized findings include poorly and well-designed studies. Well-designed and highly rigorous literature reviews should be positioned as potentially more inclusive of the literature and their evidence claims more heavily weighted. Researchers and practitioners benefit from having an assessment of the quality of the methods of reviews before making research-based decisions.

Additionally, this mega-review excluded grey literature, dissertations, articles written in a language other than English, and articles in journals and databases not accessible through those searched by the author. Articles identified during electronic database searches that were not located in full manuscript format through the university library systems, interlibrary loan, or Google Scholar® searches were also excluded. A further limitation of electronic searches was the use of free term keywords rather than each database's recognized thesaurus search terms. This may have resulted in omission of reviews that met inclusion criteria due to differences in indexing keywords, although unlikely given the large number of documents acquired in the original electronic search and the final number of reviews that were found and included. Exact overlap in 
reviewed articles across included literature reviews was not assessed, therefore results could have been inflated by potential double counting of article variables or authorreported themes regarding effectiveness. A further limitation is the possibility that literature reviews and meta-analyses pertaining to aided AAC intervention with children with developmental disabilities were overlooked and not included in this review; however, the use of hand searches and ancestral searches minimized this risk.

Due to the preponderance of single-case research design studies completed in this area and few randomized control trial or group design studies analyzed in this megareview, we were limited in our ability to compare interventions, AAC devices and programs, and dependent variables such as participant age, race, gender, disability, setting of intervention, interventionist, and dosage of intervention. Effect sizes reported by meta-analyses and systematic reviews were not comparable due to measuring different dependent variables, using different measurement systems, and reporting non-standardized effect sizes. We could not compare different designs or report intervention effects across reviews. Researchers conducting meta-analyses could use multilevel modeling and report design-comparable standardized effect sizes to facilitate comparisons across single case studies and group designs. Due to the inability to combine and compare effect sizes across designs and reviews, this mega-review only reported the conclusions made by review authors.

Finally, the inability to evaluate the articles for publication bias might be considered a limitation. Selection of studies for publication is possibly skewed toward studies with positive results, particularly large effect sizes, resulting in omission of nonsignificant results and studies with poor outcomes from inclusion in meta-analyses (Hedges, 1984; Shadish et al., 2014). While single case designs are increasingly reporting statistical effect sizes, decisions on whether to publish studies demonstrating strong functional relations and not publishing weak or no effects could result in publication bias (Shadish et al., 2014). Tests for publication bias assess whether studies with low precision have different effects than studies with high: this does not actually assess publication bias. Statistical tools cannot be used to evaluate publication bias for the reviews included in the present mega-review because the included reviews focused on different types of interventions and had different dependent variables that were impossible to aggregate using current statistical measures and raw data were not provided in the reviews, which precluded generating standardized data to calculate effect sizes.

\section{Future Directions}

There are many areas in which researchers can add to the knowledge base on aided AAC interventions for individuals with developmental disabilities, including comparing interventions, programming for generalization throughout intervention phases, assessing maintenance at longer intervals, using natural change agents and settings, and reporting between case effect sizes. Another future direction for the field is to compose an evidence and gap map to synthesize systematic reviews and primary intervention studies to summarize the entire field of AAC research (Saran \& White, 2018).

Establishing evidence-based practices is another future direction for the field. Synthesizing well-designed and methodologically rigorous studies, applying criteria for evidence-based practices, and disseminating this information across researchers, clinicians, practitioners, and consumers is are areas of need. Many AAC interventions 
are emerging or promising practices, but further efforts to establish evidence-based practices will improve quality of life outcomes for consumer and clinician decisionmaking and increase communication access for individuals with complex communication needs. AAC as an intervention practice was recently established as an evidence based practice by the National Clearinghouse on Autism Evidence and Practice Review Team (Steinbrunner et al., 2020), but further investigation into specific AAC interventions for individuals with autism spectrum disorder and AAC as an evidence-based practice for individuals with other categories of human difference is warranted.

\section{Conclusion}

This mega-review highlights steps toward improving the quality of procedures and information provided by systematic literature reviews and meta-analyses and suggests several areas of future research for interventions for children with developmental disabilities and complex communication needs who use aided augmentative and alternative communication. Increasing generalization and maintenance programming before intervention begins, reporting out greater detail on participant demographics and skills, and ensuring that lasting, socially important behavior change takes place will improve quality of life for individuals who use AAC.

Funding This research was partially supported by a United States Department of Special Education Office for Special Education Programs Leadership Grant \#H325D150082, co-primary investigators Laura Lee McIntyre, Kent McIntosh, and Wendy Machalicek.

\section{Declarations}

Conflict of Interest The authors have no conflicts of interest to report.

Ethical Approval This research was exempt from ethical approval by the Institutional Review Board at the University of Oregon. No human participants were involved in this research synthesis. Non-published data from this mega-review are available upon request, including original coding sheet and list of excluded reviews.

\section{References}

\section{Reviews included in the mega-review are indicated with *}

Aguilar, J.M., White, P.J., Fragale, C., \& Chan, J.M. (2016). Preference for language of instruction of an English language learner with autism. Developmental Neurorehabilitation, 19(3), 207-210.

*Allen, A.A., Schlosser, R.W., Brock, K.L., \& Shane, H.C. (2017). The effectiveness of aided augmented input techniques for persons with developmental disabilities: A systematic review. Augmentative and Alternative Communication, 33(3), 149-159. https://doi.org/10.1080/07434618.2017.1338752.

*Alper, S., \& Raharinirina, S. (2006). Asssistive technology for individuals with disabilities: A review and synthesis of the literature. Journal of Special Education Technology, 21(2), 47-64. https://doi.org/10. $1177 / 016264340602100204$.

*Alquraini, T., \& Gut, D. (2012). Critical components of successful inclusion of students with severe disabilities: Literature review. International Journal of Special Education, 27(1), 42-59. 
*Alsayedhassan, B., Banda, D.R., \& Griffin-Shirley, N. (2016). A review of picture exchange communication interventions implemented by parents and practitioners. Child \& Family Behavior Therapy, 38(3), 191208.

Alwell, M., \& Cobb, B. (2009). Social and communicative interventions and transition outcomes for youth with disabilities: A systematic review. Career Development for Exceptional Individuals, 32(2), 94-107. https://doi.org/10.1177/0885728809336657.

*Alzrayer, N., Banda, D.R., \& Koul, R.K. (2014). Use of iPad/iPods with individuals with autism and other developmental disabilities: A meta-analysis of communication interventions. Review Journal of Autism and Developmental Disorders, 1, 179-191. https://doi.org/10.1007/s40489-014-0018-5.

*Andzik, N.R., Cannella-Malone, H.I., \& Sigafoos, J. (2016). Practitioner-implemented functional communication training: A review of the literature. Research and Practice for Persons with Severe Disabilities, 41(2), 79-89. https://doi.org/10.1177/1540796916633874.

*Anttila, H., Samuelsson, K., Salminen, A.-L., \& Brandt, Å. (2012). Quality of evidence of assistive technology interventions for people with disability: An overview of systematic reviews. Technology and Disability, 24(1), 9-48.

Arzubiaga, A. E., Artiles, A. J., King, K. A., \& Harris-Murri, N. (2008). Beyond research on cultural minorities: Challenges and implications of research as situated cultural practice. Exceptional Children, 74(3), 309-327.

Ashby, C. E., Woodfield, C., \& Delia, Q. (2016). Communication is the root of necessity: Constructing communicative competence. In M. Cosier \& C. E. Ashby (Eds.), Enacting change from within: Disability studies meets teaching and teacher education. Peter Lang.

Bailey, S., Boddy, K., Briscoe, S., \& Morris, C. (2015). Involving disabled children and young people as partners in research: A systematic review. Child: Care, Health and Development, 41(4), 505-514.

*Barker, M.R., Saunders, K.J., \& Brady, N.C. (2012). Reading instruction for children who use AAC: Considerations in the pursuit of generalizable results. Augmentative and Alternative Communication, 28(3), 160-170. https://doi.org/10.3109/07434618.2012.704523.

*Barton, E.E., Pustejovsky, J.E., Maggin, D.M., \& Reichow, B. (2017). Technology-aided instruction and intervention for students with ASD: A meta-analysis using novel methods of estimating effect sizes for single-case research. Remedial and Special Education, 38(6), 371-386. https://doi.org/10.1177/ 0741932517729508 .

*Battaglia, D., \& McDonald, M.E. (2015). Effects of the picture exchange communication system (PECS) on maladaptive behavior in children with autism spectrum disorders (ASD): A review of the literature. Journal of the American Academy of Special Education Professionals, 2003, 8-20.

Baxter, S., Enderby, P., Evans, P., \& Judge, S. (2012). Barriers and facilitators to the use of high-technology augmentative and alternative communication devices: A systematic review and qualitative synthesis. International Journal of Language \& Communication Disorders, 47(2), 115-129.

Beukelman, D. R., \& Mirenda, P. (2013). Augmentative and alternative communication: Supporting children and adults with complex communication needs. Baltimore, MD: Paul H. Brookes Publishing Company.

*Biggs, E. E., Carter, E. W., \& Gilson, C. B. (2018). Systematic review of interventions involving aided AAC modeling for children with complex communication needs. American Journal on Intellectual and Developmental Disabilities, 123(5), 443-473. https://doi.org/10.1352/1944-7558-123.5.443.

Binger, C., \& Light, J. (2008). The morphology and syntax of individuals who use AAC: Research review and implications for effective practice. Augmentative and Alternative Communication, 24(2), 123-138.

Bondy, A. S., \& Frost, L. A. (1994). The picture exchange communication system. Focus on Autistic Behavior, 9(3), 1-19.

*Boyle, S., McCoy, A., McNaughton, D., \& Light, J. (2017). Using digital texts in interactive reading activities for children with language delays and disorders: A review of the research literature and pilot study. Seminars in Speech and Language, 38(04), 263-275. https://doi.org/10.1055/s-0037-1604274.

*Branson, D., \& Demchak, M. (2009). The use of augmentative and alternative communication methods with infants and toddlers with disabilities: A research review. Augmentative and Alternative Communication, 25(4), 274-286. https://doi.org/10.3109/07434610903384529.

*Brunner, D. L., \& Seung, H. (2009). Evaluation of the efficacy of communication-based treatments for autism spectrum disorders: A literature review. Communication Disorders Quarterly, 31(1), 15-41. https://doi.org/10.1177/1525740108324097.

*Brunner, M., Hemsley, B., Togher, L., \& Palmer, S. (2017). Technology and its role in rehabilitation for people with cognitive-communication disability following a traumatic brain injury (TBI). Brain Injury, 31(8), 1028-1043. https://doi.org/10.1080/02699052.2017.1292429. 
*Bryant, B.R., Bryant, D.P., Shih, M., \& Seok, S. (2010). Assistive technology and supports provision: A selective review of the literature and proposed areas of application. Exceptionality, 18(4), 203-213. https://oi.org/10.1080/09362835.2010.513925.

Bryen, Diane. (2009). Vocabulary to support socially-valued adult roles. Augmentative and alternative communication (Baltimore, Md.: 1985). 24. 294-301. https://doi.org/10.1080/07434610802467354.

Calculator, S. N. (1988). Promoting the acquisition and generalization of conversational skills by individuals with severe disabilities. AAC: Augmentative and Alternative Communication, 4(2), 94-103.

*Campbel, P.H., Dugan, L.M., \& Wilcox, M.J. (2006). A review of evidence on practices for teaching young children to use assistive technology devices. Topics in Early Childhood Special Education, 26(1), 3-13.

Chan, D.M., \& Zoellick, M.R.B. (2011). World report on disability, 24. World Health Organization.

*Chapin, S., McNaughton, D., Boyle, S., \& Babb, S. (2018). Effects of peer support interventions on the communication of preschoolers with autism spectrum disorder: A systematic review. Seminars in Speech and Language, 39(5), 443-457. https://doi.org/10.1055/s-0038-1670670.

*Chung, Y.-C., Carter, E.W., \& Sisco, L.G. (2012). A systematic review of interventions to increase peer interactions for students with complex communication challenges. Research \& Practice for Persons with Severe Disabilities, 37(4), 271-287.

Cooper, L., Balandin, S., \& Trembath, D. (2009). The loneliness experiences of young adults with cerebral palsy who use alternative and augmentative communication. Augmentative and Alternative Communication, 25(3), 154-164.

Crenshaw, K., Gotanda, N., Peller, G., \& Thomas, K. (Eds.). (1996). Critical race theory: The key writings that formed the movement. The New Press.

*Cumming, T.M., \& Draper Rodríguez, C. (2017). A meta-analysis of mobile technology supporting individuals with disabilities. The Journal of Special Education, 51(3), 164-176. https://doi.org/10.1177/ 0022466917713983.

*de Barbosa, R.T. A., de Oliveira, A.S.B., de Lima Antão, J.Y.F., Crocetta, T.B., Guarnieri, R., Antunes, T. P. C., ... de Abreu, L. C. (2018). Augmentative and alternative communication in children with Down's syndrome: A systematic review. BMC Pediatrics, 18(1), 1-16. https://doi.org/10.1186/s12887-018-11445 .

Desideri, L., Roentgen, U., Hoogerwerf, E. J., \& de Witte, L. (2013). Recommending assistive technology (AT) for children with multiple disabilities: A systematic review and qualitative synthesis of models and instruments for AT professionals. Technology and Disability, 25(1), 3-13.

*Douglas, S.N. (2012). Teaching paraeducators to support the communication of individuals who use augmentative and alternative communication: A literature review. Current Issues in Education, 15(1), $1-13$.

Drager, K., Light, J., \& McNaughton, D. (2010). Effects of AAC interventions on communication and language for young children with complex communication needs. Journal of Pediatric Rehabilitation Medicine, 3(4), 303-310.

Dragioti, E., Karathanos, V., Gerdle, B., \& Evangelou, E. (2017). Does psychotherapy work? An umbrella review of meta-analyses of randomized controlled trials. Acta Psychiatrica Scandinavica, 136(3), 236246. https://doi.org/10.1111/acps. 12713.

Duke, T. S. (2011). Lesbian, gay, bisexual, and transgender youth with disabilities: A meta-synthesis. Journal of LGBT Youth, 8(1), 1-52. https://doi.org/10.1080/19361653.2011.519181.

*Dunst, C.J., Trivette, C.M., Hamby, D.W., \& Simkus, A. (2013). Systematic review of studies promoting the use of assistive technology devices by young children with disabilities. Practical Evaluation Reports, 5(1) $1-32$.

*Erdem, D.R. (2017). Students with special educational needs and assistive technologies: A literature review. The Turkish Online Journal of Educational Technology, 16(1), 20.

*Flippin, M., Reszka, S., Watson, L.R. (2010) Effectiveness of the picture exchange communication system (PECS) on communication and speech for children with autism Spectrum disorders: A meta-analysis. American Journal of Speech-Language Pathology, 19(1), 178-195.

Forness, S. R., Kavale, K. A., Blum, I. M., \& Lloyd, J. W. (1997). Mega-analysis of meta-analyses: What works in special education and related services. Teaching Exceptional Children, 29(6), 4-9.

Fuller, D., Lloyd, L. L., \& Stratton, M. (1997). Aided AAC symbols. In L. L. Lloyd, D. Fuller, \& H. Arvidson (Eds.), Augmentative and alternative communication: A handbook of clinical principles and practices (pp. 48-79). Boston: Allyn \& Bacon.

*Ganz, J.B., Davis, J.L., Lund, E.M., Goodwyn, F.D., \& Simpson, R.L. (2012a). Meta-analysis of PECS with individuals with ASD: Investigation of targeted versus non-targeted outcomes, participant characteristics, and implementation phase. Research in Developmental Disabilities, 33(2), 406-418. 
*Ganz, J.B., Earles-Vollrath, T.L., Heath, A.K., Parker, R.I., Rispoli, M.J., \& Duran, J.B. (2012b). A metaanalysis of single case research studies on aided augmentative and alternative communication systems with individuals with autism spectrum disorders. Journal of Autism and Developmental Disorders, 42(1), 60-74. https://doi.org/10.1007/s10803-011-1212-2.

*Ganz, J.B., Mason, R.A., Goodwyn, F.D., Boles, M.B., Heath, A.K., \& Davis, J.L. (2014a). Interaction of participant characteristics and type of AAC with individuals with ASD: A meta-analysis. American Journal on Intellectual and Developmental Disabilities, 119(6), 516-535. https://doi.org/10.1352/19447558-119.6.516.

*Ganz, J.B., Rispoli, M.J., Mason, R.A., \& Hong, E.R. (2014b). Moderation of effects of AAC based on setting and types of aided AAC on outcome variables: An aggregate study of single-case research with individuals with ASD. Developmental Neurorehabilitation, 17(3), 184-192. https://doi.org/10.3109/ 17518423.2012 .748097$.

*Ganz, J.B., Morin, K.L., Foster, M.J., Vannest, K.J., Genç Tosun, D., Gregori, E.V., \& Gerow, S.L. (2017). High-technology augmentative and alternative communication for individuals with intellectual and developmental disabilities and complex communication needs: A meta-analysis. Augmentative and Alternative Communication, 33(4), 224-238. https://doi.org/10.1080/07434618.2017.1373855.

Gevarter, C., \& Zamora, C. (2018). Naturalistic speech-generating device interventions for children with complex communication needs: A systematic review of single-subject studies. American Journal of Speech-Language Pathology, 27(3), 1073-1090.

*Gevarter, C., O’Reilly, M.F., Rojeski, L., Sammarco, N., Lang, R., Lancioni, G.E., \& Sigafoos, J. (2013). Comparisons of intervention components within augmentative and alternative communication systems for individuals with developmental disabilities: A review of the literature. Research in Developmental Disabilities, 34(12), 4404-4414. https://doi.org/10.1016/j.ridd.2013.09.018.

*Gilson, C.B., Carter, E.W., \& Biggs, E.E. (2017). Systematic review of instructional methods to teach employment skills to secondary students with intellectual and developmental disabilities. Research and Practice for Persons with Severe Disabilities, 42(2), 89-107. https://doi.org/10.1177/ 1540796917698831.

Halle, J., Brady, N. C., \& Drasgow, E. (2004). Enhancing socially adaptive communicative repairs of beginning communicators with disabilities. American Journal of Speech-Language Pathology, 13(1), 43-54.

*Hart, S.L., \& Banda, D.R. (2010). Picture exchange communication system with individuals with developmental disabilities: A meta-analysis of single subject studies. Remedial and Special Education, 31(6), 476-488. https://doi.org/10.1177/0741932509338354.

*Heath, A. K., Ganz, J. B., Parker, R., Burke, M., \& Ninci, J. (2015). A meta-analytic review of functional communication training across mode of communication, age, and disability. Review Journal of Autism and Developmental Disorders, 2(2), 155-166.

*Holyfield, C., Drager, K.D.R., Kremkow, J.M.D., \& Light, J. (2017). Systematic review of AAC intervention research for adolescents and adults with autism spectrum disorder. Augmentative and Alternative Communication, 33(4), 201-212. https://doi.org/10.1080/07434618.2017.1370495.

*Hong, E.R., Gong, L., Ninci, J., Morin, K., Davis, J.L., Kawaminami, S., Shi, Y., Noro, F. (2017). A metaanalysis of single-case research on the use of tablet-mediated interventions for persons with ASD. Research in Developmental Disabilities, 70, 198-214. https://doi.org/10.1016/j.ridd.2017.09.013.

Horner, R. H., Carr, E. G., Halle, J., McGee, G., Odom, S., \& Wolery, M. (2005). The use of single-subject research to identify evidence-based practice in special education. Exceptional Children, 71(2), 165-179.

Howes, C. (1983). Patterns of friendship. Child Development, 54(4), 1041-1053. https://doi.org/10.2307/ 1129908.

*Iacono, T., Trembath, D., \& Erickson, S. (2016). The role of augmentative and alternative communication for children with autism: Current status and future trends

Individuals with Disabilities Education Improvement Act. 20 U.S.C. § 1400. (2004).

Ioannidis, J. P. (2009). Integration of evidence from multiple meta-analyses: A primer on umbrella reviews, treatment networks and multiple treatments meta-analyses. CMAJ, 181(8), 488-493.

Kagohara, D. M., van der Meer, L., Ramdoss, S., O’Reilly, M. F., Lancioni, G. E., Davis, T. N., ... \& Sigafoos, J. (2013). Using iPods $®$ and iPads $®$ in teaching programs for individuals with developmental disabilities: A systematic review. Research in developmental disabilities, 34(1), 147-156.

*Kent-Walsh, J., Murza, K.A., Malani, M.D., \& Binger, C. (2015). Effects of communication partner instruction on the communication of individuals using AAC: A meta-analysis. Augmentative and Alternative Communication, 31(4), 271-284. https://doi.org/10.3109/07434618.2015.1052153. 
*Kim, J., \& Kimm, C. (2017). Functional technology for individuals with intellectual disabilities: Metaanalysis of mobile device-based interventions. The Journal of Special Education Apprenticeship, (6)1, 123.

Kratochwill, T.R., Hitchcock, J., Levin, J.R., Odom, S.L., Rindskopf, D.M., \& Shadish, W.R. (2010). Singlecase designs technical documentation: Version 1.0 (pilot), $O($ June), 1-34. Retrieved from http://ies.ed.gov/ ncee/wwc/pdf/wwc_scd.pdf

Kulkarni, S. S., \& Parmar, J. (2017). Culturally and linguistically diverse student and family perspectives of AAC. Augmentative and Alternative Communication, 33(3), 170-180.

Kunze, M., Drew, C., Machalicek, W., Safer-Lichtenstein, J., \& Crowe, B. (2019). Language preference of a multilingual individual with disabilities using a speech-generating device. Behavior Analysis in Practice, 12(4), 777-781.

*Lancioni, G.E., O’Reilly, M.F., \& Basili, G. (2001). Use of microswitches and speech output systems with people with severe/profound intellectual or multiple disabilities: A literature review. Research in Developmental Disabilities, 22(1), 21-40. https://doi.org/10.1016/S0891-4222(00)00064-0.

*Lancioni, G.E., O’Reilly, M.F., Cuvo, A.J., Singh, N.N., Sigafoos, J., \& Didden, R. (2007). PECS and VOCAs to enable students with developmental disabilities to make requests: An overview of the literature. Research in Developmental Disabilities, 28, 468-488. https://doi.org/10.1016/j.ridd.2006.06. 003 .

Leko, M. M. (2014). The value of qualitative methods in social validity research. Remedial and Special Education, 35(5), 275-286. https://doi.org/10.1177/0741932514524002.

Light, J., \& McNaughton, D. (2012). The changing face of augmentative and alternative communication: Past, present, and future challenges. Augmentative and Alternative Communication, 28(4), 197-204. https:// doi.org/10.3109/07434618.2012.737024.

Light, J. C., Beukelman, D. R., \& Reichle, J. (2003). Communicative competence for individuals who use $A A C$ : From research to effective practice. Brookes Publishing.

*Logan, K., Iacono, T., \& Trembath, D. (2017). A systematic review of research into aided AAC to increase social-communication functions in children with autism spectrum disorder. Augmentative and Alternative Communication, 33(1), 51-64. https://doi.org/10.1080/07434618.2016.1267795.

*Lorah, E.R., Parnell, A., Whitby, P.S., \& Hantula, D. (2015). A systematic review of tablet computers and portable media players as speech-generating devices for individuals with autism spectrum disorder. Journal of Autism and Developmental Disorders, 45(12), 3792-3804. https://doi.org/10.1007/s10803014-2314-4.

Lorenz, R. C., Matthias, K., Pieper, D., Wegewitz, U., Morche, J., Nocon, M., et al. (2019). A psychometric study found AMSTAR 2 to be a valid and moderately reliable appraisal tool. Journal of Clinical Epidemiology, 114, 133-140.

*Lynch, Y., McCleary, M., \& Smith, M. (2018). Instructional strategies used in direct AAC interventions with children to support graphic symbol learning: A systematic review. Child Language Teaching and Therapy, 34(1), 23-36. https://doi.org/10.1177/0265659018755524.

Mace, F. C., \& Nevin, J. A. (2017). Maintenance, generalization, and treatment relapse: A behavioral momentum analysis. Education and Treatment of Children, 40(1), 27-42. https://doi.org/10.1353/etc. 2017.0001.

*Machalicek, W., Sanford, A., Lang, R., Rispoli, M., Molfenter, N., \& Mbeseha, M.K. (2010). Literacy interventions for students with physical and developmental disabilities who use aided AAC devices: A systematic review. Journal of Developmental and Physical Disabilities, 22(3), 219-240. https://doi.org/ 10.1007/s10882-009-9175-3.

*Mancil, G.R. (2006). Functional communication training: A review of the literature related to children with autism. Education and Training in Developmental Disabilities, 41(3), 213-224.

Manolov, R., Guilera, G., \& Solanas, A. (2017). Issues and advances in the systematic review of single-case research: A commentary on the exemplars. Remedial and Special Education, 38(6), 387-393.

*Millar, D.C., Light, J.C., \& Schlosser, R.W. (2006). The impact of augmentative and alternative communication intervention on the speech production of individuals with developmental disabilities: A research review. Journal of Speech, Language, and Hearing Research, 49(2), 248-264.

Mirenda, P. (2001). Autism, augmentative communication, and assistive technology: What do we really know? Focus on Autism and Other Developmental Disabilities, 16(3), 141-151. https://doi.org/10.1177/ 108835760101600302

Mirenda, P. (2003). Toward functional augmentative and alternative communication for students with autism: Manual signs, graphic symbols, and voice output communication aids. Language, Speech \& Hearing Services in Schools, 34(3), 203-216. 
Moher, D., Tetzlaff, J., Altman, D. G., \& The PRISMA Group. (2009). Preferred reporting items for systematic analyses: The PRISMA statement. PLoS Medicine, 6(7), e1000097.

*Morin, K.L., Ganz, J.B., Gregori, E.V., Foster, M.J., Gerow, S.L., Genç-Tosun, D., \& Hong, E.R. (2018). A systematic quality review of high-tech AAC interventions as an evidence-based practice. Augmentative and Alternative Communication, 34(2), 104-117. https://doi.org/10.1080/07434618.2018.1458900.

*Muharib, R., \& Alzrayer, N. (2018). The use of high-tech speech-generating devices as an evidence-based practice for children with autism Spectrum disorders: A meta-analysis. Review Journal of Autism and Developmental Disorders, 5, 43-57.

Munn, Z., Peters, M. D., Stern, C., Tufanaru, C., McArthur, A., \& Aromataris, E. (2018). Systematic review or scoping review? Guidance for authors when choosing between a systematic or scoping review approach. BMC Medical Research Methodology, 18(1), 1-7. https://doi.org/10.1186/s12874-018-0611-X.

*Murray, E., McCabe, P., \& Ballard, K.J. (2014). A systematic review of treatment outcomes for children with childhood apraxia of speech. American Journal of Speech-Language Pathology, 23(3), 486-504.

*Nam, S., Kim, J., \& Sparks, S. (2018). An overview of review studies on effectiveness of major AAC systems for individuals with developmental disabilities including autism. The Journal of Special Education Apprenticeship, 7(2), 1-14.

*O'Neill, T., Light, J., \& Pope, L. (2018). Effects of interventions that include aided augmentative and alternative communication input on the communication of individuals with complex communication needs: A meta-analysis. Journal of Speech, Language, and Hearing Research, 61, 1743-1765. https://doi. org/10.1044/2018 JSLHR-L-17-0132.

*Odom, S.L., Thompson, J.L., Hedges, S., Boyd, B.A., Dykstra, J.R., Duda, M.A., Szidon, K.L., Smith, L.E., \& Bord, A. (2015). Technology-aided interventions and instruction for adolescents with autism spectrum disorder. Journal of Autism and Developmental Disorders, 45(12), 3805-3819. https://doi.org/10.1007/ s10803-014-2320-6.

*Ok, M.W. (2018). Use of iPads as assistive technology for students with disabilities. TechTrends, 62(1), 95102. https://doi.org/10.1007/s11528-017-0199-8.

*Ostryn, C., Wolfe, P.S., \& Rusch, F.R. (2008. A review and analysis of the picture exchange communication system (PECS) for individuals with autism spectrum disorders using a paradigm of communication competence. Research \& Practice for Persons with Severe Disabilities, (33)1-2, 13-24.

* Østvik, J., Ytterhus, B., \& Balandin, S. (2017). Friendship between children using augmentative and alternative communication and peers: A systematic literature review. Journal of Intellectual \& Developmental Disability, 42(4), 403-415. https://doi.org/10.3109/13668250.2016.1247949.

Pieper, D., Buechter, R. B., Li, L., Prediger, B., \& Eikermann, M. (2015). Systematic review found AMSTAR, but not R(evised)-AMSTAR, to have good measurement properties. Journal of Clinical Epidemiology, 68(5), 574-583.

Pieper, D., Puljak, L., González-Lorenzo, M., \& Minozzi, S. (2019). Minor differences were found between AMSTAR 2 and ROBIS in the assessment of systematic reviews including both randomized and nonrandomized studies. Journal of Clinical Epidemiology, 108, 26-33.

*Pinto, P., Simpson, C., \& Bakken, J.P. (2009). Research-based instructions to increase communication skills for students with severe disabilities. International Journal of Special Education, 24(3), 12.

*Preston, D., \& Carter, M. (2009). A review of the efficacy of the picture exchange communication system intervention. Journal of Autism and Developmental Disorders, 39(10), 1471-1486. https://doi.org/10. 1007/s10803-009-0763-y.

*Ramdoss, S., Lang, R., Mulloy, A., Franco, J., O’Reilly, M., Didden, R., \& Lancioni, G. (2011). Use of computer-based interventions to teach communication skills to children with autism spectrum disorders: A systematic review. Journal of Behavioral Education, 20, 55-76. https://doi.org/10.1007/s10864-0109112-7.

*Rispoli, M.J., Franco, J.H., Van Der Meer, L., Lang, R., \& Camargo, S.P.H. (2010). The use of speechgenerating devices in communication interventions for individuals with developmental disabilities: A review of the literature. Developmental Neurorehabilitation, 13(4), 276-293. https://doi.org/10.3109/ 17518421003636794.

*Roche, L., Sigafoos, J., Lancioni, G.E., O’Reilly, M.F., Green, V.A., Sutherland, D., Van Der Meer, L., Schlosser, R.W., Marschik, P.B., Edrisinha, C.D. (2014). Tangible symbols as an AAC option for individuals with developmental disabilities: A systematic review of intervention studies. Augmentative and Alternative Communication, 30(1), 28-39. https://doi.org/10.3109/07434618.2013.878958.

*Roche, L., Sigafoos, J., Lancioni, G.E., O’Reilly, M.F., \& Green, V.A. (2015). Microswitch technology for enabling self-determined responding in children with profound and multiple disabilities: A systematic review. Augmentative and Alternative Communication, 31(3), 246-258. https://doi.org/10.3109/ 07434618.2015.1024888. 
Romski, M., Sevcik, R. A., Barton-Hulsey, A., \& Whitmore, A. S. (2015). Early intervention and AAC: What a difference 30 years makes. Augmentative and Alternative Communication, 31(3), 181-202.

Saran, A., \& White, H. (2018). Evidence and gap maps: A comparison of different approaches. Campbell Systematic Reviews, 14(1), 1-38.

*Schlosser, R.W.; Blischak, D.M. (2001). Is there a role for speech output in interventions for persons with autism? Focus on Autism and Other Developmental Disabilities, 16(3), 170-178.

Schlosser, R., \& Lee, D. (2000). Promoting generalization and maintenance in augmentative and alternative communication: A meta-analysis of 20 years of effectiveness research. Augmentative and Alternative Communication, 16(4), 208-226.

Schlosser, R. W., \& Sigafoos, J. (2006). Augmentative and alternative communication interventions for persons with developmental disabilities: Narrative review of comparative single-subject experimental studies. Research in Developmental Disabilities, 27(1), 1-29.

*Schlosser, R. \& Wendt, O. (2008). Effects of augmentative and alternative communication intervention on speech production in children with autism: A systematic review. American Journal of Speech-Language Pathology, 212-230, 17.

*Schlosser, R.W., Balandin, S., Hemsley, B., Iacono, T., Probst, P., \& von Tetzchner, S. (2014). Facilitated communication and authorship: A systematic review. Augmentative and Alternative Communication, 30(4), 359-368. https://doi.org/10.3109/07434618.2014.971490.

Schwartz, I. S., \& Baer, D. M. (1991). Social validity assessments: Is current practice state of the art? Journal of Applied Behavior Analysis, 24(2), 189-204. https://doi.org/10.1901/jaba.1991.24-189.

Seida, J. K., Ospina, M. B., Karkhaneh, M., Hartling, L., Smith, V., \& Clark, B. (2009). Systematic reviews of psychosocial interventions for autism: An umbrella review. Developmental Medicine \& Child Neurology, 51(2), 95-104.

*Sennott, S.C., Light, J.C., \& McNaughton, D. (2016). AAC modeling intervention research review. Research and Practice for Persons with Severe Disabilities, 41(2), 101-115. https://doi.org/10.1177/ 1540796916638822.

Sharif, M. O., Janjua-Sharif, F. N., Ali, H., \& Ahmed, F. (2013). Systematic reviews explained: AMSTARhow to tell the good from the bad and the ugly. Oral Health Dent Manag, 12(1), 9-16.

Shea, B. J., Grimshaw, J. M., Wells, G. A., Boers, M., Andersson, N., Hamel, C., Porter, A. C., Tugwell, P., Moher, D., \& Bouter, L. M. (2007). Development of AMSTAR: A measurement tool to assess the methodological quality of systematic reviews. BMC Medical Research Methodology, 7, 1-7. https://doi. org/10.1186/1471-2288-7-10.

Shea, B. J., Reeves, B. C., Wells, G., Thuku, M., Hamel, C., Moran, J., Moher, D., Tugwell, P., Welch, V., Kristjansson, E., \& Henry, D. A. (2017). AMSTAR 2: A critical appraisal tool for systematic reviews that include randomised or non-randomised studies of healthcare interventions, or both. BMJ, 358, j4008.

*Shire, S.Y., \& Jones, N. (2015). Communication partners supporting children with complex communication needs who use AAC: A systematic review. Communication Disorders Quarterly, 37(1), 3-15. https://doi. org/10.1177/1525740114558254.

*Sievers, S. B., Trembath, D., \& Westerveld, M. (2018). A systematic review of predictors, moderators, and mediators of augmentative and alternative communication (AAC) outcomes for children with autism spectrum disorder. Augmentative and Alternative Communication, 34(3), 291-229. https://doi.org/10. 1080/07434618.2018.1462849.

Sinclair, J., Hansen, S. G., Machalicek, W., Knowles, C., Hirano, K. A., Dolata, J. K., Blakely, A. W., Seeley, J., \& Murray, C. (2018). A 16-year review of participant diversity in intervention research across a selection of 12 special education journals. Exceptional Children, 84(3), 312-329. https://doi.org/10.1177/ 0014402918756989.

Singer, G. H., Agran, M., \& Spooner, F. (2017). Evidence-based and values-based practices for people with severe disabilities. Research and Practice for Persons with Severe Disabilities, 42(1), 62-72.

Smith, M. (2015). Adolescence and AAC: Intervention challenges and possible solutions. Communication Disorders Quarterly, 36(2), 112-118.

*Smith, T. \& Iadarola, S. (2015). Evidence base update for autism spectrum disorder. Journal of Clinical Child and Adolescent Psychology, 44(6), 897-922. https://doi.org/10.1080/15374416.2015.1077448.

*Snell, M.E., Chen, L.Y., \& Hoover, K. (2006). Teaching augmentative and alternative communication to students with severe disabilities: A review of intervention research 1997-2003. Research and Practice for Persons with Severe Disabilities. https://doi.org/10.1177/154079690603100301, 31, 203, 214.

Spear, C. F., Strickland-Cohen, M. K., Romer, N., \& Albin, R. W. (2013). An examination of social validity within single-case research with students with emotional and behavioral disorders. Remedial and Special Education, 34(6), 357-370. https://doi.org/10.1177/0741932513490809. 
*Stauter, D.W., Myers, S.R., \& Classen, A.I. (2017). Literacy instruction for young children with severe speech and physical impairments: A systematic review. Journal of Occupational Therapy, Schools, \& Early Intervention, 10(4), 389-407. https://doi.org/10.1080/19411243.2017.1359132.

Steinbrenner, J. R., Hume, K., Odom, S. L., Morin, K. L., Nowell, S. W., Tomaszewski, B., Szendrey, S., McIntyre, N. S., Yücesoy-Özkan, S., \& Savage, M. N. (2020). Evidence-based practices for children, youth, and young adults with autism. In The University of North Carolina at Chapel Hill. Frank Porter Graham Child Development Institute: National Clearinghouse on Autism Evidence and Practice Review Team.

*Stephenson, J., \& Limbrick, L. (2015). A review of the use of touch-screen mobile devices by people with developmental disabilities. Journal of Autism and Developmental Disorders, 45(12), 3777-3791. https:// doi.org/10.1007/s10803-013-1878-8.

*Still, K., Rehfeldt, R.A., Whelan, R., May, R., \& Dymond, S. (2014). Facilitating requesting skills using high-tech augmentative and alternative communication devices with individuals with autism spectrum disorders: A systematic review. Research in Autism Spectrum Disorders, 8(9), 1184-1199. https://doi.org/ 10.1016/j.rasd.2014.06.003.

*Sulzer-Azaroff, B., Hoffman, A.O., Horton, C.B., Bondy, A., \& Frost, L. (2009). The picture exchange communication system (PECS): What do the data say? Focus on Autism and Other Developmental Disabilities, 24(2), 89-103. https://doi.org/10.1177/1088357609332743.

*Therrien, M.C.S., Light, J., \& Pope, L. (2016). Systematic review of the effects of interventions to promote peer interactions for children who use aided AAC. Augmentative and Alternative Communication, 32(2), 81-93. https://doi.org/10.3109/07434618.2016.1146331.

*Tien, K.-C. (2008). Effectiveness of the picture exchange communication system as a functional communication intervention for individuals with autism Spectrum disorders: A practice- based research synthesis. Education and Training in Developmental Disabilities, 43(1), 61-76.

*Tincani, M., \& Devis, K. (2011). Quantitative synthesis and component analysis of single-participant studies on the picture exchange communication system. Remedial and Special Education, 32(6), 458-470. https://doi.org/10.1177/0741932510362494.

Trembath, D., Balandin, S., \& Togher, L. (2007). Vocabulary selection for Australian children who use augmentative and alternative communication. Journal of Intellectual and Developmental Disability, 32(4), 291-301.

Uman, L. S. (2011). Systematic reviews and meta-analyses. Journal of the Canadian Academy of Child and Adolescent Psychiatry, 20(1), 57-59.

*van Der Meer, L.A.J., \& Rispoli, M. (2010). Communication interventions involving speech-generating devices for children with autism: A review of the literature. Developmental Neurorehabilitation, 13(4), 294-306. https://doi.org/10.3109/17518421003671494.

*van Der Meer, L., Sigafoos, J., O’Reilly, M.F., \& Lancioni, G.E. (2011). Assessing preferences for AAC options in communication interventions for individuals with developmental disabilities: A review of the literature. Research in Developmental Disabilities, 32(5), 1422-1431. https://doi.org/10.1016/j.ridd.2011. 02.003 .

Walker, V. L., \& Snell, M. E. (2013). Effects of augmentative and alternative communication on challenging behavior: A meta-analysis. Augmentative and Alternative Communication, 29(2), 117-131. https://doi. org/10.3109/07434618.2013.785020.

*Walker, V.L., Lyon, K.J., Loman, S.L., \& Sennott, S. (2018). A systematic review of functional communication training (FCT) interventions involving augmentative and alternative communication in school settings. Augmentative and Alternative Communication, 34(2), 118-129. https://doi.org/10.1080/ 07434618.2018.1461240.

Wells, K., \& Littell, J. H. (2009). Study quality assessment in systematic reviews of research on intervention effects. Research on Social Work Practice, 19(1), 52-62.

Publisher's Note Springer Nature remains neutral with regard to jurisdictional claims in published maps and institutional affiliations. 